\title{
RENUNCIAR A UN IDEAL REVOLUCIONARIO: EL DEBATE EN TORNO A LA NATURALEZA PRIVADA Y COMUNAL DE LA REFORMA AGRARIA MEXICANA*
}

\author{
Eitan Ginzberg \\ Universidad de Tel Aviv
}

\begin{abstract}
Entonces se pensó en el ejido. Más bien dicho, no se pensó, sino que por mero instinto comprendimos que el ejido era el único medio de transición para pasar de la grande a la pequeña propiedad.

Luis Cabrera, Veinte años después: las dos revoluciones, México, Botas,1938, p. 272.
\end{abstract}

Fecha de recepción: 8 de marzo de 2018

Fecha de aceptación: 16 de enero de 2019

* Agradezco a los lectores anónimos por haber aportado importantes observaciones que contribuyeron a mejorar notablemente el manuscrito. Deseo agradecer al Dr. Marcelo Blidstein, director de la Biblioteca Académica del Colegio de Ingeniería Afeka de Tel Aviv por el valioso material de archivo referente al presidente Álvaro Obregón y su época; a la Dra. Belina Neuberger y a la traductora del texto al español, por su trabajo fiel y acertado que culminó en una excelente traducción y por el tratamiento dedicado por el equipo editorial que facilitó la publicación del proyecto. 
[...] surge la presunción o la sospecha, quizás no muy aventurada, de que lo que en el fondo se busca es ir minando y destruyendo, poco a poco o de golpe, la pequeña propiedad, con la tendencia de suprimirla, en virtud de considerarla un estorbo para la colectivización agraria....

Antonio Díaz Soto y Gama, La cuestión agraria en México, Ediciones El Caballito, 1976, p. 104.

\section{EL PROBLEMA}

U

no de los compromisos sociales más destacados de la revolución mexicana -y quizá el más significativo- fue la entrega de parcelas a todos los mexicanos, hombres y mujeres, cuya subsistencia dependiera del trabajo agrícola, pero que no tuvieran acceso a tierras propias. Tras una larga deliberación sobre la "obsesión nacional", como denominaba el debate Manuel Bonilla, secretario de Relaciones Exteriores de Francisco Madero (debate que comenzó en 1909 con la publicación del libro de Andrés Molina Enríquez, Los grandes problemas nacionales), ${ }^{1}$ se concibieron dos métodos claramente distintos para redistribuir los recursos agrícolas del país: el comunal (o compartido), llamado ejido, ${ }^{2}$ y el individual, basado en parcelas

${ }^{1}$ Bonilla, Apuntes, p. 139.

2 El ejido es una creación sui generis única y dinámica de México. Los ejidos formaban parte de la comunidad colonial indígena, se utilizaban sobre todo para la recreación, el pastoreo y la silvicultura, y se ubicaban en la periferia de la comunidad. La premisa del ejido moderno en tanto comunidad agrícola corporativa surgió en 1912, tras años de restricciones militares y políticas, y de estabilización del régimen revolucionario. El ejido adquirió su interpretación final moderna el 22 de marzo de 1916, en una reunión de la Comisión Nacional Agraria, con las palabras del secretario de Agricultura y Desarrollo y director de la Comisión, Pastor Rouaix. Sobre esta interpretación, véase ArboleydA CASTro, El nacimiento del ejido moderno, pp. 42-45. Véanse también, en relación con este tema: Recopilación de leyes, p. 199; CABRERA, La reconstitución 
familiares de propiedad vitalicia conocidas con varios nombres, como pequeña propiedad, home stead [sic] mexicano, propiedad patrimonial, patrimonio de familia, patrimonio de una familia o propiedad de familia.

Sin embargo, la mayoría de los participantes (en la controversia agraria que culminó con la formulación del artículo 27 de la Constitución de 1917), provenientes de una amplia gama de contextos intelectuales, parlamentarios, políticos, legales y militares, a ambos lados ideológicos de la Revolución, apoyaban la opción de la pequeña propiedad. Ello en contraposición a la alternativa ejidal, considerada por algunos de los concurrentes -como Luis Vicente Cabrera, abogado y miembro de la Cámara de Diputados por la ciudad de México, o Miguel Ángel de Quevedo, ingeniero y experto en silvicultura- como un arreglo transitorio que pudiera constituir una fuente de ingresos y cuyo objetivo fuera preparar a los campesinos para la reforma "real", es decir, la agricultura de familia.

En realidad, lo que surgió fue algo distinto. Desde principios de la década de 1920, y de manera más enfática durante el gobierno de Lázaro Cárdenas (1934-1940), los ejidos transitorios se convirtieron en un modelo nacional exclusivo para la distribución de la tierra en el campo. En cambio, la idea de la pequeña propiedad en tan prometedor proyecto revolucionario de rehabilitación nacional desapareció casi por completo. A nuestro parecer, la principal razón de este cambio fue el artículo 27 de la Constitución, que no sólo buscaba sentar las bases para una reforma agraria de amplio alcance en México, sino también dividir el poder entre el centro político y su periferia federal dentro de un sistema de controles y equilibrios, mediante la separación de la autoridad legal encargada de llevar a cabo la reforma

de los ejidos, pp. 298-309; Orozco, Los ejidos de los pueblos, pp. 50, 183-184; Emilio Kourí, "La invención del ejido", Nexos (10 ene. 2015); Wolfe, "The Sociolegal Redesignation of Ejido Land Use, 1856-1912”, pp. 298-309. 
de la tierra. Mientras que el centro político sería responsable de implementar la reforma comunal "provisional" y "transitoria", los estados federados estarían a cargo de implementar la reforma de la pequeña propiedad. ${ }^{3}$ Sin embargo, esta división del poder originó en el centro político la sospecha de que los autores del artículo 27 intentaban debilitarlo en beneficio de los estados federados, situación que no podía aceptar.

Venustiano Carranza, quien probablemente previó las consecuencias de una convención constituyente entusiasta, presentó un borrador que reflejaba la idea plasmada en el artículo de 27 de la Constitución de 1857 de privatizar desde el centro todas las tierras corporativas o bienes de manos muertas. ${ }^{4}$ Cuando no logró convencer al comité redactor del artículo 27 -Pastor Rouaix, presidente; Molina Enríquez, secretario-asesor; y Luis Cabrera y Miguel Ángel de Quevedo, invitados en calidad de asesores- de adoptar su borrador, dio un paso atrás. Aunque podría haber resentido el "ataque frontal tan contrario a su

${ }^{3}$ Véase el discurso de Pedro de Alba en Diario de los debates de la Cámara de Diputados del Congreso de los Estados Unidos Mexicanos, Legislatura XXIX, año II, t. III, núm. 26, sesión del 9 de noviembre de 1921, primer periodo extraordinario (en adelante, Ley de Fraccionamiento de Latifundios), 6 de mayo de 1921, p. 9. (El doctor De Alba era representante del estado de Aguascalientes.) Al definir la ley agraria de enero de 1915 -legislada por Carranza con la autoridad que le confería su cargo de Primer Jefe del Ejército Constitucionalista- como constitucional, el artículo 27 determinaba, por inferencia, que la reforma ejidal, punto crucial de la ley de enero de 1915, estaría encabezada por el gobierno central. La redacción del artículo 27 se hallaba en el centro de la disputa que se desató en la Cámara de Diputados durante el debate de la primavera y el verano de 1921 en torno a la autoridad federal para presentar una propuesta sobre la autoridad de los estados. "Para que pudiera aprobarse esta ley atentatoria que propone a vuestra soberanía la Comisión”, afirmó el diputado Luis Espinosa durante el debate, "habría que reformar la Constitución". Véase Ley de fraccionamiento de latifundios, 18 de abril de 1921, p. 26.

4 Cumberland, Mexico: The Struggle for Modernity, pp. 261-262, 265-266; The Mexican Constitution of 1917, pp. 15-25; UlLOA, "La Constitución de 1917”, p. 28; Elizondo, The Concept of Property, p. 7. 
propia filosofía [agraria]”, cuando la asamblea constituyente desestimó su borrador, "no protestó ni hizo comentarios en público", según escribe Charles Cumberland. Su decisión fue distinta, a saber, "ampararse bajo el precepto colonial virreinal de 'Obedezco pero no cumplo'”. ${ }^{5}$ Así, cuando en diciembre de 1917 miembros de la Cámara de Diputados presentaron para su aprobación una ley sobre la disolución de latifundios en el Distrito Federal y los territorios de Quintana Roo y Baja California -una primera acción significativa para desmantelar los latifundios de la federación, ${ }^{6}$ y sin duda una maniobra para alentar tanto a las autoridades ejecutivas como a los estados a fomentar este tema dentro de sus jurisdicciones-, Carranza se encargó de que ésta fuera abrogada. ${ }^{7}$

Al mismo tiempo, en una alarmante respuesta para evitar maniobras similares, Carranza devolvió a los grandes latifundistas propiedades que habían sido expropiadas por sus gobernadores militares en el fragor de la batalla y distribuidas como pequeñas propiedades entre campesinos pobres. ${ }^{8}$ Hacia fines de 1918, cuando en cierta forma se reconcilió con el tema agrario, presentó al Congreso un proyecto de ley que formulaba las reglas para el artículo 27, y que resultó ser una copia casi exacta de su ley ejidal de enero de 1915. El asunto de la expropiación de latifundios

${ }^{5}$ Cumberland, Mexico: The Struggle for Modernity, p. 267.

6 Utilizo el término "latifundio", que estaba mucho más difundido en el discurso político y legal del México revolucionario, que el término similar "hacienda". El primer censo agrario, de 1930, indica un control latifundista (1000 o más hectáreas por finca) del $76.7 \%$ de la tierra agrícola cultivada en México en ese entonces. Véase Tello, La tenencia de la tierra en México, pp. 18-19. En el debate parlamentario que se halla en el centro de este artículo, el término "latifundio" se menciona 1358 veces, mientras que el término "hacienda" sólo se menciona 253 veces.

7 Diario de los debates de la Cámara de Diputados, Legislatura XXVII, t. II, núm. 88, sesión del 20 de diciembre de 1917, pp. 6-8.

8 Ibarra Mendibil, Ejido y control estatal, pp. 98-99 y nota 36, p. 99; Álvaro Obregón, "Carta al Licenciado Roque Estrada (19 de diciembre de 1919), en Bassols, Elpensamiento político de Álvaro Obregón, pp. 137-138. 
para dividirlos en pequeñas propiedades se había omitido. ${ }^{9} \mathrm{El}$ resultado de un segundo intento legislativo por desmantelar los latifundios del Distrito Federal y los Territorios, presentado para su discusión y consideración en la Cámara de Diputados el 13 de octubre de 1920 por diputados del bloque agrario del Congreso, fue muy similar. Como ya había ocurrido, la renovada propuesta fue discutida brevemente y luego congelada. ${ }^{10} \mathrm{Ni}$ Carranza en 1917 ni el presidente interino Adolfo de la Huerta en 1920 mostraron ningún interés en abordar un problema de tal magnitud. ${ }^{11}$

Obregón intentó atacar el problema de forma distinta. En lugar de congelar la reforma agraria en sus vertientes ejidal y de pequeña propiedad, su idea era adoptarlas y tomar el control al mismo tiempo. En principio, apoyaba una reforma limitada de las tierras privadas, pero tenía serias dudas sobre disolver los latifundios antes de que las pequeñas fincas privadas demostraran su eficacia. ${ }^{12}$ Obregón abordó esta contradicción en octubre de 1920 en una reunión con miembros de la Cámara de Diputados dedicada a las disposiciones legales requeridas para implementar el artículo 27 a la luz de este enfoque. En la reunión, reconoció

9 Silva Herzog, El agrarismo mexicano, pp. 263-264.

10 Diario de los debates de la Cámara de Diputados, Legislatura XXIX, año I, t. I, núm. 42, pp. 34-37, sesión del 13 de octubre de 1920.

${ }^{11}$ Carranza tuvo mucho cuidado de no interferir con la propiedad privada de ninguna forma, aun cuando su uso estuviera relacionado con la Ley de Tierras Ociosas, aprobada en el Congreso desde 1917. Carranza hizo todo lo posible para no promulgar la ley. Primero la vetó (1918) y más adelante la congeló (1919). Sobre esta saga, véanse "Proyecto de ley por el que se declara de utilidad pública el cultivo de las tierras de labor en México", en XXVII Congreso de la Unión, 1918, pp. 43-44; "Informe de Don Venustiano Carranza al abrir el Congreso sus sesiones ordinarias el 1 de septiembre de 1919", en Los presidentes de México ante la nación, t. III (1912-1934), 1966, p. 244; El Universal (25 y 26 dic. 1919); Excelsior (26 dic. 1919).

12 Álvaro Obregón, El problema agrícola y agrario. Conferencia dada en la Cámara Agrícola Jalisciense el día 18 de noviembre de 1919, Guadalajara, 1922, p. 7. 
que los campesinos mexicanos aspiraban a establecer pequeñas propiedades privadas y progresivas. Esto podía lograrse, decía, disolviendo los latifundios de manera gradual: primero los ineficientes y después, luego de que las pequeñas fincas demostraran que podían ser exitosas, los productivos. Obregón calculaba que, en total, se dedicarían al proyecto alrededor de 50 millones de hectáreas de la tierra agrícola en México. Seis millones de hectáreas serían asignadas como ejidos a un millón de campesinos que no pudieran dedicarse a la agricultura avanzada, mientras que los 44 millones de hectáreas restantes se utilizarían para crear pequeñas propiedades dedicadas a la agricultura sustentable (la cantidad de beneficiarios no se especificaba, aunque estadísticas posteriores para ese periodo mencionan alrededor de 2 millones de posibles propietarios campesinos)..$^{13}$ Con el fin de alentar a estos últimos a hacer la transición, los campesinos recibirían la formación necesaria para ayudarlos a implementar métodos de agricultura avanzada, mientras que sus derechos a la tierra serían garantizados mediante una ingeniosa ley, en el espíritu de "los sustanciales intereses colectivos que me dieron a mí [Obregón] su apoyo”. ${ }^{14}$

Defendiendo su filosofía, ${ }^{15}$ Obregón presentó dos iniciativas de ley al Congreso mexicano: una sobre ejidos en diciembre de $1920,{ }^{16}$ y otra sobre la expropiación de los latifundios y su división planeada en fincas de familia en febrero de 1921. La primera propuesta era la parte más fácil del trato, aunque sólo fuera porque se desprendía de una autoridad implícita otorgada

${ }^{13}$ Quinto censo de población (1930), p. 40.

14 Álvaro Obregón, "El problema agrario. Versión taquigráfica del cambio de impresiones tenido por el presidente electo con un numeroso grupo de diputados al Congreso de la Unión”, México, octubre de 1922, pp. 7-9, 25.

${ }^{15}$ Hall, "Álvaro Obregón and the Politics of Mexican Land Reform", pp. 214-215; Brunk, Emiliano Zapata, p. 231.

16 Ley de ejidos, México, 30 de diciembre de 1920 (publicada el 8 de enero de 1921), en FabIla, Cinco siglos, pp. 346-361. 
constitucionalmente al gobierno federal de México y que ninguno de los diputados federales cuestionaba. La segunda era más compleja: en primer lugar, desafiaba el mandato que la Constitución confería de manera manifiesta a los estados respecto de la implementación de pequeñas propiedades de familia, que iba acompañado de la autoridad para confiscar cualquier finca o, por extensión, cualquier empresa agrícola que resultara "perjudicial a los intereses sociales [de los campesinos]", con lo cual los gobiernos estatales también adquirían un enorme poder político. ${ }^{17}$ En segundo lugar, si Obregón no hubiera formulado una iniciativa de ley federal sobre la pequeña propiedad, podría haber perdido buena parte del ámbito agrario frente a los estados federados, ${ }^{18}$ de los cuales al menos nueve ya habían actuado para febrero de 1920, y otros diez estaban a punto de hacerlo. ${ }^{19}$ Así, la ley propuesta en febrero de 1921 constituía un intento por someter todo el ámbito agrario al control federal y establecer una especie de equilibrio entre la redistribución privada y la ejidal, antes de que la primera superara a la segunda y despojara al centro federal de una influencia significativa sobre la reforma agraria. ${ }^{20}$ Esto se manifestó de manera clara en el feroz debate

17 Ley de fraccionamiento de latifundios, sesión de 7 de abril de 1921, p. 8. Cuando se discutió en la Cámara, la ley solía mencionarse como "Ley de Fraccionamiento de Latifundios", aunque también como "Ley de División de Latifundios". Véanse, por ejemplo, las sesiones del 27 de abril de 1921, pp. 14-15; 10 de julio de 1921, p. 4, y 4 de julio, p. 7.

${ }_{18}$ Hall, "Álvaro Obregón and the Politics of Mexican Land Reform," pp. 217-218, 233-237.

19 Véase un cuadro comparativo de leyes estatales en Fabila y Ursúa, Fraccionamiento de latifundios, pp. 44, 56-57, y en Tannenbaum, The Mexican Agrarian Revolution, pp. 432-450.

20 En 1916, Salvador Alvarado, gobernador de Yucatán, a quien Arnaldo Córdova describía como "luchador honesto y sincero, amigo de las clases más humildes de la Sociedad", dijo: "El ejido, ó sea el terreno de uso comunal, es rudimentario, porque no da seguridad al trabajador para el goce constante de su lote, puesto que siempre se temen nuevas divisiones de la tierra, lo cual no anima a consolidar el hogar [...] y darle estabilidad al trabajador de campo", en 
sobre el tema del home stead que tuvo lugar en la Cámara de Diputados.

El dilema que enfrentó Obregón en 1921 fue serio. Si su intención de pasar su iniciativa de ley nacional sobre la pequeña propiedad fracasaba, podía enfrentar la misma situación que Carranza y De la Huerta en diciembre de 1917 y octubre de 1920, respectivamente. Sin duda habría tenido que adoptar la misma decisión que ambos tomaron en su momento, a saber, enterrar una vertiente agraria muy apreciada y prometedora de la Revolución sobre la pequeña propiedad. De hecho, esto fue exactamente lo que ocurrió.

El objetivo de este artículo es estudiar el debate parlamentario que condujo a este callejón sin salida y examinar sus consecuencias. Estas deliberaciones tuvieron lugar en la Cámara de Diputados entre el 7 de abril y el 26 de julio de 1921, y giraron en torno a una propuesta legislativa federal, supuestamente inocente, que se concentraba en la expropiación y división de todas las fincas socialmente "ofensivas" de México en propiedades de familia que serían vendidas a cualquier campesino en condiciones muy favorables. El artículo 3 de la ley propuesta por Obregón definía como "ofensiva" cualquier finca que resultara "perjudicial a los intereses sociales, bien porque engendre el monopolio de la producción agrícola en la región donde se encuentre ubicada, ya porque contribuya a provocar crisis de carestía o escasez en los artículos alimenticios, o porque [...] obstruya, por cualquiera otra causa, el desarrollo agrícola del país". Por esta razón, obstaculizaba el derecho natural de cualquier hombre "para poseer y cultivar para sí una superficie de terreno cuyo rendimiento, dada una aplicación media de trabajo, sea bastante para satisfacer sus propias necesidades, las de su familia y para

Alvarado, A dónde vamos, p. 8. El gobernador de Durango, Agustín Castro, dijo algo similar en 1922 (véase p. 34). 
permitirle la formación de un pequeño ahorro, con el que pueda hacer frente a las eventualidades del porvenir". ${ }^{21}$

El debate concluyó cuando la amplia mayoría de la Cámara decidió despojar a la ley de su aporte nacional y convertirla en una legislación sin sentido que sólo afectaba al Distrito Federal y a los Territorios, cuya población rural no era significativa. Creemos que este dramático debate ha recibido poca atención en los estudios que abordan el agrarismo mexicano, a pesar de que tuvo repercusiones de largo plazo en el México rural y, sin lugar a duda, en todo el país. En este sentido, el presente artículo podría constituir una nueva perspectiva sobre el enorme proyecto agrario mexicano, sobre sus contratiempos y caminos retorcidos que iban y venían entre la esperanza y la decepción, y que concluyó formalmente a principios de 1992 con un sentimiento de profunda desilusión. ${ }^{22}$

Además de las minutas del debate de 1921, y de las de otros debates relevantes de las Cámaras de Diputados y Senadores entre 1917 y principios de la década de 1960, en la actualidad disponemos de un sinnúmero de fuentes de principios del siglo xx hasta nuestros días, algunas de ellas escritas por los diseñadores originales de los métodos agrarios de México: revolucionarios, elaboradores de políticas intelectuales, abogados y legisladores. Éstas incluyen documentos y certificados recopilados a partir de los archivos de la reforma agraria en Veracruz y Michoacán, dos estados con índices de reforma especialmente altos en México (12 y 6\%, respectivamente), y de 25 años de

21 Ley de fraccionamiento de latifundios, 7 de abril de 1921, p. 8.

${ }^{22}$ Durante la reforma, se establecieron o extendieron 27664 comunidades ejidales en un proceso de dotación, y se restauraron tierras para $2278 \mathrm{comu}$ nidades indígenas en un proceso de restitución. Desde la conclusión de la reforma hasta 2004 se agregaron 1034 nuevos ejidos. A lo largo de la reforma se distribuyeron 106 millones de hectáreas entre 4210830 campesinos. Véase Salazar AdAme, La cuestión agraria en la transición, pp. 7, 27. Datos ligeramente mayores revelan 31514 ejidos y comunidades, en Resultados del IX Censo Ejidal 2007, cuadros 1 y 12. 
reuniones, entre 1989 y 2014, con ejidatarios y particulares, así como con funcionarios asignados o electos para la reforma. Estos valiosos recursos podrían echar luz sobre algunos aspectos cruciales de la reforma agraria mexicana y sus dos trayectorias: la que se dejó atrás y la que se mantuvo y ganó exclusividad, a pesar de las numerosas reticencias, junto con otros proyectos menores de restitución de tierras a comunidades indígenas.

\section{EL DEBATE SOBRE LA PEQUEÑA PROPIEDAD}

Con la "ley de la pequeña propiedad” que presentó a la Cámara de Diputados, Obregón esperaba “acabar con los parias de la República y hacer de cada campesino un propietario de su parcela y un propietario de su felicidad", como lo dijo su secretario de Agricultura, Antonio Villarreal, que fue invitado a la segunda sesión del debate parlamentario sobre la iniciativa de ley.

En comparación con las tres hectáreas de tierra ejidal, el propósito de la iniciativa era asignar parcelas de entre 10 y 20 hectáreas a cada campesino (que recibía varios nombres, como fraccionista, parcionista, adjudicatario de parcela, pequeño propietario o pequeño terrateniente), cada una de las cuales tenía acceso a agua. ${ }^{23}$ Si dicha tierra no pudiera encontrarse (la tierra de riego era un lujo escaso en el paisaje mexicano de la década de 1920), los campesinos recibirían entre 20 y 40 hectáreas de tierra de temporal de “1a. clase”, entre 30 y 60 hectáreas de tierra del mismo tipo de " 2 a. clase”, o bien entre 40 y 80 hectáreas de tierra de "3a. clase”, es decir, tierra no irrigada. Además, todos los campesinos eran elegibles para recibir hasta 100 hectáreas extra de tierra "para cría de ganados”. De acuerdo con la ley, a los ganaderos podían concedérseles hasta 200 hectáreas, “siempre que no se perjudique el derecho de las solicitudes de tierra

\footnotetext{
${ }^{23}$ En relación con las especificaciones relativas del ejido, véase Ley de fraccionamiento de latifundios, 7 de abril, Art. 9, p. 9.
} 
laborable". ${ }^{24}$ Empero, a diferencia de las políticas ejidales, la tierra no se ofertaba libre de costo. Los solicitantes tenían que pagar su valor fiscal (es decir, su valor catastral) más 10\% y "más un cinco por ciento por concepto de gastos de planificación y fraccionamiento y otro cuatro por ciento sobre el capital insoluto", con el fin de cubrir los gastos incurridos por el gobierno para llevar a cabo la reforma. Dicho monto debía cubrirse en pagos en efectivo a un plazo de 20 años, o bien en forma de bonos de la Deuda Agraria Nacional a una tasa de interés de hasta 4\% anual. La Deuda Agraria Nacional, a su vez, debía transferir el dinero a los terratenientes o propietarios expropiados en forma de bonos pagados en un plazo de 20 años. ${ }^{25}$

Los individuos elegibles para recibir tierras (tomadas, como ya se mencionó, de fincas "antisociales") eran principalmente aparceros, arrendatarios, jornaleros o peones, y se daba prioridad a jefes de familia casados de ambos sexos. ${ }^{26} \mathrm{El}$ derecho a solicitar tierras se confería a ciudadanos mexicanos, así como a personas que estuvieran esperando la ciudadanía -con prioridad para individuos que vivieran cerca de una propiedad designada para la expropiación-, siempre y cuando no tuvieran extensiones de tierra más grandes que lo estipulado en la ley. Los campesinos recibían la tierra de manera condicional, pues su propiedad les era otorgada sólo cuando completaban el proceso de adquisición. ${ }^{27}$

Las secciones transitorias de la ley estipulaban que a los latifundistas que ofrecieran dividir su tierra de manera voluntaria se les permitiría hacerlo en un plazo de entre tres y cinco meses. Más adelante, estas secciones declaraban que la ley habría de servir de guía para la legislación de todos los estados federales,

${ }^{24}$ Ley de fraccionamiento de latifundios, 7 de abril, Art. 9, p. 9.

${ }^{25}$ Ley de fraccionamiento de latifundios, 7 de abril, Arts. 38, 40, 44, 48, pp. 11-12.

26 Ley de fraccionamiento de latifundios, 7 de abril, Arts. 3 y 4, p. 8.

27 Ley de fraccionamiento de latifundios, 7 de abril, Arts. 13-15, 21, p. 9. 
y que en cuanto dichas leyes fueran aprobadas, sustituirían a la ley federal. También declaraban que el gobierno federal promovería una ley especial para alentar el establecimiento de cooperativas y colonias, con el fin de reducir el daño causado por la transición de una estructura latifundista a una basada en pequeñas propiedades, y hacer la agricultura más eficiente. Además, estas secciones estipulaban que la ley federal de ese momento no sustituiría a las leyes ejidales, sino que más bien existiría al mismo tiempo como una opción adicional disponible para todos los campesinos.

El cambio propuesto por la ley fue presentado como un gran avance económico, conforme a las recomendaciones de los expertos y al artículo 27 de la Constitución, con "el pensamiento y el sentimiento de la clase agraria del país”-incluidos los indígenas $-{ }^{28}$ y con la visión agraria nacional de Miguel Hidalgo, padre y precursor de la independencia mexicana. ${ }^{29}$ La ley, como lo declaraban sus defensores, debía poner a México al día con "la evolución de las naciones" hacia la "familia de las civilizaciones modernas". ${ }^{30}$ Sería "la creación de un poderoso factor de progreso económico, en armonía con los modernos postulados de la ciencia y, sobre todo, con las necesidades del país”. ${ }^{31}$

Más aún, los miembros de los dos comités agrarios de la Cámara de Diputados afirmaron que la iniciativa de ley podía tener una influencia capital en la Revolución, pues el éxito o fracaso de los planes de reconstrucción nacional dependían de su existencia. El proyecto estaba supeditado por completo a la creación de una sociedad de pequeños propietarios agrícolas, de la cual dependía la verdadera libertad económica, una sociedad que generara

${ }^{28}$ Ley de fraccionamiento de latifundios, 22 de abril, p. 19; 26 de abril, p. 15.

${ }^{29}$ Ley de fraccionamiento de latifundios, 18 de abril, p. 7.

30 Ley de fraccionamiento de latifundios, 18 de abril, p. 8.

${ }^{31}$ Ley de fraccionamiento de latifundios, 30 de mayo, p. 5. 
[...] el ciudadano independiente, el aumento de producción que equilibrará nuestras finanzas, la mejor repartición de la riqueza, que resolverá hasta cierto límite las desigualdades sociales en su forma más dolorosa, y permitirá romper los primeros lazos de la explotación del hombre por el hombre, siendo, por tanto, el crisol caldeado con la sangre de tantos mártires en que va a fundirse la nacionalidad y la raza, para salir de allá más fuertes y ennoblecidos por el esfuerzo, por el trabajo pacífico y constante con que se forja la verdadera grandeza de los pueblos. ${ }^{32}$

Además, la ley se presentó como si reflejara "los pensamientos hasta hoy dispersos de los intelectuales agraristas", y afirmara "el derecho de todos los ciudadanos a una fracción de terreno", basado en el derecho absoluto a usar o destruir la propiedad (jus utendi et abutendi). ${ }^{33}$ Como ya se expuso, esta iniciativa compensaría de alguna forma "la sangre derramada en holocausto" (es decir, la revolución mexicana de 1910-1917) en palabras del diputado zapatista de Morelos, Octavio Paz Solórzano, padre del poeta y ganador del premio Nobel de literatura, Octavio Paz Lozano. ${ }^{34}$

No es de sorprender que esta retórica tan idealista y emocional por parte de los defensores de la ley fuera una introducción a un acalorado debate intelectual sobre la iniciativa. Este debate reflejó enfoques ideológicos, conceptuales e interpretativos en la historia, filosofía y derecho de Oriente y Occidente: desde la antigua China, Grecia y la Roma clásica, pasando por la conquista de América y el debate se prolongó durante 46 sesiones, en su mayoría extensas, entre el 7 de abril y el 25 de julio de 1921..$^{35}$ Buena parte de los debates se concentró en tres preguntas

${ }^{32}$ Ley de fraccionamiento de latifundios, 7 de abril, p. 8.

${ }^{33}$ Ley de fraccionamiento de latifundios, 7 de abril, p. 8.

${ }^{34}$ Ley de fraccionamiento de latifundios, 4 de mayo, p. 11.

${ }^{35}$ Ley de fraccionamiento de latifundios, sesiones de 7, 18, 22, 25, 26, 27 y 28 de abril de 1921; 3, 4, 6, 10,11, 12, 13, 18, 19, 20, 23, 24, 25, 27, 30 y 31 de mayo 
básicas: ¿tendría el Congreso federal la autoridad para crear una ley que abordaba un área puesta por la Constitución bajo la jurisdicción de los estados federales? ¿Sería la ley capaz de establecer criterios adecuados para definir una propiedad "grande", de modo que pudiera identificarse, y llevar a cabo su expropiación y distribución entre los campesinos pobres? Y finalmente, ¿ ¿debía ser la propiedad que habría de otorgarse a los campesinos tras haber completado el proceso de adquisición una suerte de propiedad "protegida", es decir, una propiedad salvaguardada para siempre de cualquier tipo de apropiación, transacción comercial o hipoteca financiera, salvo mediante la aprobación especial de la Comisión Nacional Agraria, como lo exigía la iniciativa propuesta? O bien, ¿¿debía la posesión (a menudo calificada como de pleno dominio o de derecho absoluto) seguir a pie juntillas los principios del derecho romano sobre propiedad privada y, por ende, no tener ninguna reserva sobre su uso y ser definida como "propiedad perfecta" o "propiedad de dominio pleno", como la mayoría de los diputados lo demandaba?

Los defensores de la legislación, seguidores del bloque democrático-socialista que afiliaba a comunistas, socialistas y agraristas del Partido Nacional Agrarista, ${ }^{36}$ respondían afirmativamente las primeras dos preguntas y la primera opción de la tercera. Por medio de su principal vocero, Antonio Díaz Soto y Gama, presidente del primer Comité Agrario de la Cámara de Diputados y fundador y líder del Partido Nacional Agrarista, argumentaron (respecto de la primera pregunta) que resultaba absurdo tener 28 distintas interpretaciones y soluciones al problema agrario en México, "cuantos son los Estados, o de otra manera, que son 27 los Estados de la República más el Distrito

de $1921 ; 1,2,6,7,14,15,16,20,21,23,24$ y 29 de junio de 1921; 1, 4, 6, 8, 11, 13, 19, 20, 21, 22 y 25 de julio de 1921.

${ }^{36}$ El partido fue fundado el 13 de junio de 1920 por Antonio Díaz Soto y Gama bajo los auspicios de Obregón. Véase Womack Jr., Zapata and the Mexican Revolution, pp. 496-497. 
Federal”. "Esto sólo puede caber”, agregó Soto y Gama, “en un cerebro desequilibrado", totalmente incompatible con la intención del gobierno de que el país tenga "una solución uniforme al problema agrario", un gobierno que ansíe una ley racional y efectiva, aceptada por todas las legislaturas estatales en virtud de su naturaleza unificada, y una ley que honre, "en nombre de la revolución triunfante, de esta revolución que ha durado diez años, de que esta revolución lo único que ha pedido es lo que no se ha consignado en forma de postulado: el derecho sagrado del hombre, del mexicano, a un pedazo de tierra". ${ }^{37}$

Otro argumento, apoyado por el médico y diputado por Querétaro, José María Siurob, presidente del segundo Comité Agrario de la Cámara de Diputados, y en referencia a la misma pregunta, era que la regulación federal sobre los temas relacionados con la pequeña propiedad en el artículo 27 de la Constitución obligaría a los estados que no fueran por el mismo camino en este tema (según Siurob, todos salvo Zacatecas y San Luis Potosí) a ajustarse de inmediato. A pesar de que nueve estados ya estaban legalmente preparados para la disolución de sus latifundios, el argumento afirmaba, de manera errónea, que los estados temían enfrentar a los latifundistas y preferían no legislar sus propias leyes. ${ }^{38}$

En cuanto a la segunda pregunta, los miembros de los dos comités agrarios y sus seguidores en la Cámara sostenían que, en realidad, sólo $2.3 \%$ de los latifundios era eficiente y quedaría, por lo tanto, exento de la expropiación. Los demás latifundios - “un cáncer roedor en el organismo del pueblo", la vergüenza del país, el principal culpable de "la úlcera que agotaba lentamente la vitalidad nacional" - serían disueltos. ${ }^{39}$ Los comités agrarios también prometieron que no habría problema con la

37 Ley de fraccionamiento de latifundios, 25 de abril, p. 11.

${ }^{38}$ Ley de fraccionamiento de latifundios, 7 de abril, p. 11.

${ }^{39}$ Ley de fraccionamiento de latifundios, 18 de abril, pp. 22-23. 
definición de latifundio, pues bajo el artículo 4 de la ley, y de conformidad con los estándares más estrictos establecidos en el artículo 3, el gobierno estaba autorizado a declarar como latifundio (es decir, como tierra adecuada para la expropiación) cualquier terreno privado, sin importar su tamaño, si se comprobaba que no estaba cultivado o que estaba mal administrado, y, por ende, a legalizarlo para la expropiación y transferencia a campesinos necesitados. Más aún, puesto que la ley agregaba todas las tierras nacionales (artículo 48) a su esfera de sanciones (unos 25 millones de hectáreas en ese entonces), ${ }^{40}$ los comités agrarios de hecho prometieron que no habría escasez de tierras disponibles en la República.

En cuanto a la tercera pregunta, los miembros de los dos comités agrarios estaban convencidos de que la propiedad restringida establecida por el artículo 20 de la ley era indispensable para proteger la tierra de cualquier pérdida debida a la venta injustificada, hipoteca, usura "o cualquiera otro que limite el derecho de propiedad". Esto, declaró Soto y Gama en el debate, no era una propiedad ordinaria, sino "revolucionaria", "social”. Era una propiedad que conllevaba "una función social como la que ejerce el médico [...] como la que ejerce el sacerdote $[\ldots]$ como la que ejerce el industrial $[\ldots]$ como la que ejerce el comerciante [...] es decir, función para el interés social, no para el interés suyo". Se trataba, por lo tanto, de una propiedad "modificada" otorgada de manera condicional por la nación a un individuo como usufructo vitalicio y concesión hereditaria, mas no como la propiedad "bárbara" de la antigua Roma feudal, "de la que están enamorados los reaccionarios" y que no encajaba en ninguna sociedad moderna. La sociedad necesitaba algo distinto, bien incorporado en el artículo 27 de la Constitución:

40 Esta figura está tomada de "Informe del Don Venustiano Carranza al abrir el Congreso", en Los presidentes de México ante la nación, pp. 218-219 y 343-344. 
una propiedad que la nación pudiera regular ocasionalmente de acuerdo con sus necesidades compartidas, un tipo de propiedad consistente con las demandas de los mejores economistas de la era moderna, como Pierre Paul Leroy-Beaulieu (1843-1916), quien afirmaba que "la propiedad privada sólo está legitimada en cuanto favorece al interés social”. De tal forma,

El verdadero fundamento de la propiedad privada es la utilidad social; ya no es el derecho del primer ocupante [...] ni son todos esos mitos metafísicos que habían inventado los juristas; ahora conforme a los nuevos tratadistas, conforme a los mismos discípulos de la escuela clásica, el basamento de la justicia de la propiedad está en la utilidad pública [...] completamente opuesto al criterio individualista que veía en la propiedad a un dios.

De acuerdo con estos criterios, la Constitución, decía Soto y Gama, imponía una serie de modalidades sobre las propiedades, "bien sea para fraccionamiento de latifundios, para la destrucción de monopolios, o bien para la restitución o dotación de ejidos". ${ }^{41}$ Todavía aplicando la lógica del enfoque de la propiedad limitada, José Siurob apuntó que en México era bien sabido que:

[...] los humildes que adquieren pequeñas propiedades, cuando por cualquiera circunstancia de su miseria, de su error al cultivar aquel pedazo de tierra, se ven apurados por la necesidad, lo que hacen es inmediatamente vender su tierra y volver a constituir de una manera automática el latifundio [...]

Así ocurrió como resultado de la "Ley Juárez" (la Reforma). Los constituyentes de 1917, agregó Siurob, anticiparon este proceso y por ello rechazaron el enfoque romano jus utendi et

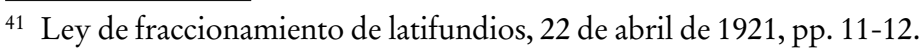


abutendi, afirmando que nada que se refiriera a la propiedad de tierra y reservas de agua podía tener derechos absolutos. ${ }^{42}$

Quienes se oponían a la ley, en su mayoría miembros del Partido Liberal Constitucionalista, que actuaban como un sólido bloque de mayoría en la Cámara, rechazaron la ley de manera rotunda. En su opinión, la ley no tenía justificación desde un punto de vista constitucional, pues invadía zonas de jurisdicción estatal, debilitando esta última e intentando asumir el control sobre ella. ${ }^{43}$ Apuntaron que algunos estados ya habían aprobado leyes que buscaban la expropiación y disociación de las grandes propiedades, de modo que no había necesidad de promulgar una ley federal al respecto. ${ }^{44} \mathrm{La}$ ley, argumentaban los opositores, ofrecía una definición de latifundio lo suficientemente vaga como para desencadenar una serie de amparos que la volverían poco práctica y que causarían una amarga decepción entre la gente, que se quedaría sin tierras. Aún peor, la ley dejaba que esta definición vaga fuera interpretada por el Ejecutivo nacional, de modo que éste siempre podría evitar la expropiación a su antojo político. En pocas palabras, se corría el riesgo de que nunca hubiera una reforma agraria.

Los opositores a la ley también argüían que la ley no definía la pequeña propiedad de manera satisfactoria, y que su enfoque de propiedad contradecía el gran mensaje de rehabilitación de las comunidades agrícolas y de la agricultura nacional que la ley buscaba presentar. De acuerdo con el diputado Rodrigo Gómez, de Durango, la propiedad incompleta de la tierra de

\footnotetext{
${ }^{42}$ Ley de fraccionamiento de latifundios, 14 de junio de 1921, p. 19.

${ }^{43}$ En este contexto, véase la mordaz argumentación presentada por el diputado del estado de Oaxaca, Eduardo Vasconcelos (después procurador de Justicia, secretario de Gobernación y Educación Pública, ministro de la Suprema Corte de Justicia y gobernador) en Ley de fraccionamiento de latifundios, 10 de mayo, p. 11.

${ }^{44}$ En pleno debate, se discutieron varios proyectos de ley relacionados con la expropiación y división de fincas, como los de Michoacán y Durango.
} 
hecho facilitaría que los latifundistas generaran situaciones en las que pudieran explotar las debilidades de los campesinos, "a los humildes, a los miserables, a los eternamente oprimidos", y echarlos de la tierra que habían adquirido con tanto trabajo. Después agregó: “¡Torpe, doloso e inmoral, sería suponer que el artículo 27 sólo puede favorecer a los ricos, a los influyentes, y nunca a los que tienen por todo capital el esfuerzo de sus músculos y la fe de su corazón!”. ${ }^{45}$ Los opositores a la ley concluyeron que ésta, tal como fue presentada ante la Cámara, no era sino precursora del caos nacional y la destrucción de la agricultura. En palabras del diputado Luis Espinosa, de Chiapas, la ley era "el cadáver de la revolución [es decir, relata Espinosa, el mismo cadáver que Zaratustra encontró cuando bajó de la colina en busca de seres humanos vivos a quienes pudiera comunicar su sabiduría], envuelto en el manto, en el sudario que el pueblo triste y miserable ha tejido con los hilos gloriosos de sus lágrimas y de su sangre [durante la Revolución]”. Y peor aún, era inconstitucional. Personificaba un ataque directo a la soberanía del Estado. Israel del Castillo, de Oaxaca, un opositor a la ley de lo más articulado y franco, la calificó de "letra muerta". ${ }^{46}$ Uriel Avilés, de Michoacán, fue particularmente mordaz y cínico al resumir las opiniones de varios opositores como sigue:

Yo sigo sosteniendo que esta ley es mala $[\ldots]$ porque esta ley no resuelve en su verdadero fondo la cuestión agraria [...] Y por eso [...] hay que aprobarla hasta que el pueblo dentro de diez, de veinte años vuelva otra vez a reaccionar, haga otra revolución y entonces inscriba en su bandera esta leyenda: hay que tomar la tierra de donde la haya... (Voces: ¡Cabrera!) [...] Yo creo, señores diputados, que el pueblo solamente podrá resolver el problema agrario en su verdadero fondo cuando haga una nueva revolución, llegue a una

${ }^{45}$ Ley de fraccionamiento de latifundios, 30 de mayo, p. 5.

${ }^{46}$ Ley de fraccionamiento de latifundios, 28 de abril, p. 15. 
hacienda y ésta la reparta a troche y moche (Risas. Aplausos.) y así siga por todos los ámbitos de la República hasta resolver, para mejor dicho el problema agrario. ${ }^{47}$

El desacuerdo fue intenso, atestado de diatribas y difamaciones: "Este pobre hombre, que responde al nombre de Antonio Díaz Soto y Gama [...] claro que tendrá la intuición como la tiene [...] el salvaje [...] el idiota”. Ello despertó resentimientos del pasado y gritos: “Voces: ¡Tribuna! ¡Sube a la Tribuna! ¡No! Escándalo ¡No, hombre! ¡No! ¡No! ¡Ya! ¡Ya! ¡A votar! ¡A votar! ¡Que hable! ¡Que hable! ¡Pruebas! ¡Pruebas! Siseos: 'Huy, huy"'.

Los defensores de la legislación, empero, no se inmutaron. Era un momento de enorme importancia nacional, decían. A menudo se hacía referencia en los debates a "la impaciencia de los campesinos”, quienes, "no pudiendo esperarse más tiempo, ya comienzan a unificarse, diciendo que si esta ley no tiene pronta aplicación, ellos tomarán la providencia de aplicarla por sus propias manos”. El deseo generalizado de tierra debía ser satisfecho de inmediato, antes de que fuera demasiado tarde. La iniciativa debía volverse operativa de inmediato, pues sólo así podía garantizarse que los estados que aún no hubieran legislado sus propias leyes para dividir los latifundios lo hicieran de inmediato. A decir verdad, deberían haberlo hecho mucho antes, siguiendo las provisiones de la Constitución, es decir, en la fecha estipulada por el artículo 27 de la Constitución, de acuerdo con el cual la legislación sobre los latifundios debía expedirse “dentro del periodo constitucional subsecuente”, "a más tardar para los años de 1918 y 1919”.48 De otra forma,

47 Ley de fraccionamiento de latifundios, 18 de abril, p. 18.

48 Palabras del diputado Guillermo Rodríguez, en Ley de fraccionamiento de latifundios, 25 de julio, p. 10. Véase también Ley de fraccionamiento de latifundios, 13 y 30 de mayo. 
La respuesta está viva en la miseria del proletariado campesino, traducida en el hambre de millares de mexicanos que por un momento, al constituirse cada Gobierno revolucionario, permiten que en su espíritu nazca una nueva esperanza de redención que, casi siempre, para vergüenza nuestra, se cambia en un doloroso desengaño. ${ }^{49}$

En este sentido, sostenían sus defensores, la ley propuesta era una clara declaración del gobierno central para poner "una [sic] hasta aquí, a ese estado inconstitucional, a ese estado fuera del pacto federal, a ese estado contrario a la ley base de nuestras instituciones". ${ }^{50}$ Las críticas estaban dirigidas a los estados que estaban tardando en legislar la división de sus latifundios como lo requería el artículo 27 de la Constitución.

En este contexto, un grupo de diputados del estado de Hidalgo, con una postura más equilibrada respecto de la ley, argumentó que varios estados habían suspendido todas las legislaciones sobre la pequeña propiedad de manera intencional, con el pretexto de que no tenían el permiso federal para crear una deuda agraria para pagar los latifundios expropiados (autoridad que los estados ya debían haber adquirido para ese entonces con base en el texto del artículo 27, que exigía al Congreso Nacional regular este tema en un corto lapso de tiempo). Los diputados argumentaban que la verdadera razón era que dichos estados estaban hastiados de enfrentar a los latifundistas. Este aplazamiento, afirmaban, era un crimen contra la nación "contrario a los intereses sociales” y sancionable bajo la sección $21 \mathrm{del}$ artículo 73 de la Constitución. ${ }^{51}$

\footnotetext{
49 Ley de fraccionamiento de latifundios, 30 de mayo, p. 5.

50 Ley de fraccionamiento de latifundios, 30 de mayo, p. 5.

51 Ley de fraccionamiento de latifundios, 30 de mayo, p. 5. Evidentemente, los diputados de Hidalgo confundieron a la Cámara. La mayoría de los estados no dudaron en confrontar a los latifundistas, como lo evidencian los nueve estados que ya habían promulgado leyes apropiadas sobre el tema y los otros siete u ocho que estaban en el proceso de legislación. La ausencia de deudas agrarias
} 
Sin embargo, con el fin de que la reforma siguiera adelante sin trabas, los miembros de la delegación parlamentaria de Hidalgo sometieron a un voto inmediato y bien planeado una iniciativa que habían preparado meticulosamente por anticipado y que autorizaba a los estados a establecer su propia deuda agraria interna. De acuerdo con los términos de la iniciativa que, por supuesto, no tenían un valor operativo porque la Cámara no pretendía discutirlos y someterlos a votación, prometían crear una "corriente de valores realizables" y "el mejoramiento de la vida económica de la República”, sin la necesidad de más sanciones federales, necesarias mientras no hubiera una ley como la que sugería la delegación hidalguense. ${ }^{52}$

Había dos asuntos, empero, sobre los que ambas facciones concordaban: primero, que el ejido no estaba equipado para enfrentar el problema general de la pobreza rural, los retos agrícolas nacionales y las aspiraciones de los campesinos. "Ha comprendido este Gobierno", declaraba el secretario de Agricultura, que había sido invitado a la segunda sesión del debate legislativo, "que el ejido no basta para satisfacer los anhelos de los campesinos, ni [para] hacerles justicia completa a ellos y que es necesario darle a cada campesino la oportunidad de ser libre, la oportunidad de ser dueño del pedazo de tierra que cultive". ${ }^{53}$ Los

se derivaba del gran retraso en la legislación federal correspondiente, que debía establecer la base legal para la creación de deudas agrarias en los estados. Los diputados Aarón Sáenz, Emilio Portes Gil, Rafael Zepeda y Francisco Labastida ya habían presentado una ley de ese tipo al Congreso para su aprobación en 1917. Carranza, quien más bien deseaba fundar la reforma agraria en tierras nacionales, vetó esa ley. En su informe anual de 1918, Carranza prometió presentar una iniciativa propia sobre el tema, pero nunca cumplió su promesa. Véanse XXVII Congreso de la Unión, Sintesis de su labor, pp. 44-45; "Informe de Don Venustiano Carranza al abrir el Congreso”, p. 244. Obregón también siguió postergando el tema debido a su incapacidad para nacionalizar la reforma de la pequeña propiedad. Finalmente, fue el presidente Calles quien en 1925 estableció fondos de deuda pública (nota 99).

${ }^{52}$ Ley de fraccionamiento de latifundios, 30 de mayo, pp. 3-4.

${ }^{53}$ Ley de fraccionamiento de latifundios, 18 de abril, p. 22. 
campesinos, agregó Antonio Villarreal, exigen esa tierra [privada]. Lucharon durante 11 años y no están satisfechos. Siempre se les ha decepcionado. Desde Hidalgo, han recibido una reforma política, pero no una reforma agraria real.54 "Ese es el corazón de esta ley, esa es el alma de esta ley y el Ejecutivo espera que los señores diputados, como ya lo demostraron anteriormente al discutir la ley de Ejidos, estén también con el Ejecutivo y lleguen a aprobar esta ley, con el aplauso de la nación". ${ }^{55}$

El segundo asunto en que concordaban todos los miembros de la Cámara era que los campesinos que solicitaran la vía de la propiedad privada tendrían que pagar por ella. En otras palabras, a diferencia de la opción del ejido o de las tierras ociosas, que se había regulado unos meses antes, y de la opción de la colonización, que aún no estaba regulada por la ley pero que ya se había discutido ampliamente, que se consideraban libres de cargo, la reforma del home stead requería un pago. Este enfoque quedaba justificado por el hecho de que, puesto que la opción de la pequeña propiedad se vinculaba con tierras privadas cuya posesión estaba consagrada por la Constitución (artículo 14) y protegida por la ley, era imposible no pagar por ellas, pues de lo contrario su confiscación se consideraría despojo y sus beneficiarios, ladrones, maniobra que nunca pasaría la prueba en la corte. No obstante, puesto que los estados federales no podían asumir esta carga, ésta tendría que recaer en los propios campesinos.

Los presidentes de los comités agrarios presentaron tres argumentos para tranquilizar a los diputados que temían que los campesinos no pudieran asumir una carga financiera que incluyera intereses, gastos administrativos vinculados con el proceso de fraccionamiento y el gravamen ordinario cobrado a todos los propietarios. En primer lugar, afirmaron, la carga no

54 Ley de fraccionamiento de latifundios, 18 de abril, pp. 27-28.

55 Ley de fraccionamiento de latifundios, 18 de abril, p. 21. 
era tan terrible como parecía, pues los pagos sobre los bienes adquiridos se calculaban de acuerdo con su valor fiscal, que era considerablemente menor que su valor comercial. ${ }^{56} \mathrm{El} \mathrm{se-}$ gundo argumento era que, mientras los campesinos cultivaran concienzudamente la tierra que recibían, cubrir los pagos no les significaría un problema. El tercer argumento afirmaba que, de acuerdo con lo mostrado por la experiencia acumulada hasta ese momento en el ámbito de la agricultura privada, incluso cuando la transacción de la tierra se llevaba a cabo a precios exorbitantes, sobre todo en el mercado libre, ésta terminaba siendo casi siempre exitosa, de modo que al final los campesinos podían sentar cabeza. De allí que, cuando los precios de la tierra eran razonables, las probabilidades de éxito fueran indudablemente altas. ${ }^{57}$

Otro argumento -que no buscaba mitigar los temores de los diputados, sino colocar el tema en una perspectiva adecuada en el marco liberal de una revolución que respetaba la propiedad privada en el sentido constitucional y legal- estipulaba que, bajo estas condiciones ideológicas y legales, el gobierno mexicano no sólo debía garantizar el pago de las tierras privadas expropiadas,

56 En el debate no se presentaron cifras exactas sobre la diferencia entre el valor fiscal de las tierras en México y su valor real. Soto y Gama sostenía que el valor fiscal de las tierras en México era “insignificante”. Véase Ley de fraccionamiento de latifundios, $1^{\circ}$ de julio de 1921, p. 10. Sin embargo, las tierras de riego eran muy caras. En Tacuba, D.F., el valor fiscal de una hectárea era de 370 pesos, y de 492 pesos en Azcapotzalco. Ley de fraccionamiento de latifundios, 23 de mayo de 1921, pp. 16-17.

57 El diputado Luis Espinosa calculaba que una hectárea de tierra de riego costaría no menos de 300 pesos. Suponía que un hogar agrícola (bome stead) de 3.5 hectáreas con " 1 casa con dos piezas y cercada”, más " 1 tronco de mulas [...] 1 arado, guarnés, semilla y efectivo” para empezar, costaría 1650 pesos. Si todo esto se adquiría a un crédito pagadero en 20 años, el retorno anual sería de 82.50 pesos, una suma razonable que los campesinos serían capaces de cubrir. Espinosa argumentaba que la Cámara debía considerar el proyecto sobre la pequeña propiedad de manera integral, pues de lo contrario terminaría siendo un completo fiasco. Ley de fraccionamiento de latifundios, 24 de mayo de 1921, p. 27. 
sino también la credibilidad de todo su sistema económico, que dependía del cumplimiento de las obligaciones financieras involucradas. Si este sistema no funcionaba adecuadamente, el gobierno nunca podría garantizar sus bonos y reunir los capitales necesarios entre los mexicanos, ni de otra fuente extranjera, sin lo cual ningún Estado moderno podía funcionar. ${ }^{58}$ Por lo tanto, las compensaciones no sólo eran obligatorias, sino que cualquier fisura en su fiabilidad debía considerarse intolerable. Más allá del daño al Estado en tanto su garante, dicha situación sería el primer y más importante testimonio de la indiferencia de los campesinos respecto del trabajo agrícola y, por ende, razón suficiente para expulsarlos y regresar la tierra a sus propietarios legales. Además, la obligación tributaria general, tal y como estaba estipulada en el artículo 21 de la ley (que requería la compensación de la deuda, el cultivo de la tierra y el pago de los impuestos), no debía subestimarse, dada su importancia para los presupuestos federal y estatal.

Sin embargo, para enfrentar una posible crisis de pagos, los miembros de los comités agrarios de la Cámara agregaron el artículo 21 bis a la iniciativa, el cual se encargaría de los individuos que se retiraran de manera prematura del proyecto de la pequeña propiedad. El artículo les reembolsaba entre la mitad y dos terceras partes del dinero que ya había sido pagado antes de su retiro. El objetivo de esta adenda era tranquilizar a los diputados preocupados por la capacidad de los campesinos para enfrentar las exigencias monetarias del artículo 21 de la ley. En pocas palabras, la cuestión de una compensación genuina y tangible no estuvo en duda en ninguna etapa del proceso legislativo. La idea era que se trataba de una obligación que debía cumplirse y de una carga que los campesinos que se unieran al proyecto debían ser capaces de asumir.

58 Sobre las preocupaciones de México en torno a este tema, véase WiLKIE, La revolución mexicana, p. 139. 
Por último, tras una serie de duros debates, se aprobó el primer artículo de la ley, que reconocía el derecho de todos los mexicanos a poseer una parcela propia de la cual pudieran obtener su subsistencia. Esto más o menos resume el alcance del acuerdo al que se llegó tras numerosas deliberaciones. Posteriormente, no hubo casi ningún artículo en que ambos lados pudieran concordar. Cediendo ante las demandas de los opositores a la ley, que constituían mayoría en la Cámara de Diputados, la discusión fue directamente del artículo 1 a la primera sección transitoria de la ley, que establecía su aplicabilidad legal a toda la República. El debate en torno a este tema fue particularmente acalorado. Quedaba claro que quien ganara esta discusión sería prácticamente el vencedor de todo el debate. De hecho, tras una serie de deliberaciones bastante intensas y de carácter intelectual, que comprendieron cinco sesiones y una discusión de un mes, entre el 22 de abril y el 19 de mayo, el primer artículo transitorio original fue cambiado. El alcance de la aplicabilidad de la ley se limitó al Distrito Federal, con su millón de habitantes urbanos, y a los dos territorios de Baja California y Quintana Roo, que sólo comprendían 17000 habitantes rurales de una población de 14335000 habitantes en México en ese entonces, de los cuales $70 \%$ eran campesinos que dependían de la economía agrícola. ${ }^{59}$ La ley, manifiesto revolucionario nacional, había fracasado.

Pero ni siquiera el deceso de esta ley logró mitigar la furia contra los miembros de los comités agrarios de la Cámara, que habían preparado la iniciativa para su aprobación, y sus seguidores. El caos volvió a cundir cuando el debate llegó al artículo 3 de la legislación, que definía los latifundios -un tema de poca importancia en esa etapa del debate dado que los Territorios

59 MeYer, “El primer tramo del camino”, cuadro VIII, p. 1251. Las cifras poblacionales para ambos territorios se presentaron durante las mismas deliberaciones. Véase Ley de fraccionamiento de latifundios, 27 de abril de 1921, p. 4; 18 de mayo, p. 3; y 22 de mayo, p. 20. 
y el Distrito Federal sólo tenían unos cuantos, ${ }^{60}$ y el Artículo 4, que abordaba la prerrogativa del gobierno federal para decidir qué fincas debían o no considerarse como latifundios. Los ataques contra la filosofía sofisticada de los artículos -que obviamente pretendían prevenir la disolución masiva de los latifundios, al menos mientras el gobierno federal decidía que no le interesaba hacerlo- estuvieron encabezados por el diputado Luis Espinosa. El artículo tercero, afirmaba, era un gran escándalo, aun cuando sólo tuviera efecto en los Territorios y en el Distrito Federal, debido a su capacidad de amenazar cualquier reforma agraria, independientemente de la posición de la Cámara. ${ }^{61}$

¿Estaba Espinosa consciente del resultado? Podemos pensar que sí. De hecho, durante una de las últimas sesiones, Uriel Avilés declaró algo que debieron haber entendido claramente todos los miembros de la Cámara, a saber, que si la ley apenas ratificada, o lo que quedaba de ella, requiriera una segunda ratificación por parte del Senado, éste la rechazaría. ${ }^{62} \mathrm{Al}$ final, se dio el peor resultado posible, al menos desde la perspectiva de los defensores de la iniciativa: el 26 de julio, el Senado recibió un amasijo aprobado por la Cámara de Diputados, lo entregó a la Comisión de Agricultura y Desarrollo y a la Segunda Comisión de Puntos Constitucionales, y nunca la regresó para su posterior discusión. ${ }^{63}$ La relevancia de este estruendoso silencio era

60 De acuerdo con el censo agrícola de 1930, los Territorios comprendían tan sólo $1 \%$ de todas las parcelas nacionales de más de cinco hectáreas. Véase Compendio estadístico 1951, tabla 46, pp. 120-121.

${ }^{61}$ Ley de fraccionamiento de latifundios, 6 de mayo, p. 6.

${ }^{62}$ Ley de fraccionamiento de latifundios, 25 de julio, pp. 2-3.

63 Diario de los debates de la Cámara de Senadores del Congreso de los Estados Unidos Mexicanos, Legislatura XXIX, año II, t. III, núm. 26, sesión del 9 de noviembre de 1921, p. 1. De 1921 a 1922, la ley fue mencionada en el Senado de manera intermitente, así como por el propio secretario de Agricultura (en la sesión del 14 de noviembre de 1921), como un tema pendiente que requería ser completado por el bien de "los altos intereses de la Nación". Sin 
evidente: sin una ley federal de fraccionamiento de latifundios, aunque sólo se aplicara al Distrito Federal y a los Territorios, no habría ninguna reforma agraria de este tipo, como lo había vaticinado atinadamente Uriel Avilés. El problema es que los involucrados tardaron mucho en llegar a esta conclusión, tras cuatro meses de discusiones agotadoras que sólo intensificaron la rivalidad entre los bandos y les impidieron alcanzar una comprensión más cabal -lo cual, en su debido momento, podría haber empujado la iniciativa de Obregón a los márgenes federales-, en lugar de llevarlos a trabajar en un acuerdo, quizá basado en una coexistencia reglamentaria entre federación y estados, como lo sugería la delegación de Hidalgo, antes de que el programa de la pequeña propiedad fuera rechazado del todo.

Al parecer, hubo al menos cuatro razones por las que la iniciativa no prosperó: primero, los resentimientos previos entre exzapatistas (que fueron derrotados en la Revolución) y constitucionalistas (que ganaron la batalla), y el hecho de que estos últimos no estaban dispuestos a permitir que sus antiguos rivales los superaran en el Congreso y tomaran el control de la agenda nacional; segundo, la lucha entre los defensores de un Ejecutivo federal fuerte al que el Congreso estuviera subordinado (es decir, los radicales y ahora también exzapatistas, los antiguos profetas del Estado descentralizado, convocado de nuevo a la escena nacional por Obregón), ${ }^{64}$ y los seguidores liberales de Obregón, que apoyaban un Congreso fuerte y autónomo al que el

\footnotetext{
embargo, como ya se mencionó, el Senado nunca confirmó la ley de 1921. Diario de los debates de la Cámara de Senadores del Congreso de los Estados Unidos Mexicanos, año I, periodo extraordinario, t. III, núm. 28, sesión del 14 de noviembre de 1921; Diario de los debates de la Cámara de Senadores, Legislatura XXX, año I, periodo ordinario, t. I, núm 10, sesión del martes 12 de septiembre de 1922, p. 32.

${ }^{64}$ Buchenau, The Last Caudillo, p. 106; Womack JR., Zapata and the Mexican Revolution, pp. 496-502.
} 
Ejecutivo federal estuviera subordinado, ${ }^{65}$ tercero, la convicción de los representantes de la mayoría de los estados ante el Congreso de que no podrían justificar ante sus representados su apoyo a una ley federal que podía debilitar el poder de sus propios estados; y cuarto, la ilusión fomentada por los opositores a la ley de que sus estados podrían hacer frente a la cuestión agraria de manera autónoma, mientras el centro federal se quedaba cruzado de brazos observando pasivamente la completa disolución de los latifundios, que comprendían la mitad, o incluso más de la mitad de todas las tierras cultivables de México.

En consecuencia, fue Obregón quien, inmediatamente después del rechazo de su iniciativa, presionó a todos los gobernadores estatales para que no llevaran a efecto las leyes locales sobre el desmantelamiento de los latifundios y su redistribución en forma de patrimonios de familia. En Chihuahua, donde se había promulgado una ley sobre el establecimiento de la pequeña propiedad privada en mayo de 1922, Obregón no permitió que el gobernador Ignacio Enríquez la implementara. ${ }^{66}$ Despojado del apoyo federal, Enríquez renunció a principios de 1923. ${ }^{67}$ Lo mismo ocurrió con el gobernador Rafael Nieto en

${ }^{65}$ Cuando Obregón llegó a la presidencia, el Partido Liberal Constitucionalista (PLC) era el partido más poderoso del país. Como resultado, los "peleceanos” ganaron la mayoría en ambas Cámaras del Congreso. Esta luna de miel terminó en 1921, cuando el partido intentó sacar ventaja de su hegemonía parlamentaria para someter a Obregón a su autoridad y forma de pensar. Véanse Monroy Durán, El último caudillo, p. 33; Portes GiL, Autobiografía de la revolución mexicana, pp. 334-336; Hansis, “Álvaro Obregón”, pp. 103-114; Dulles, Ayer en México, pp. 119-124.

${ }^{66}$ Domínguez Rascón, La política de la reforma agraria en Chibuabua, pp. 41-42. No obstante, para responder a las presiones agrarias que venían desde abajo en Chihuahua, e ignorando la autoridad del gobernador Enríquez sobre las expropiaciones de latifundios, Obregón ordenó la compra de la propiedad de Terrazas en Chihuahua en abril de 1922. Domínguez Rascón, La política de la reforma agraria en Chibuahua, pp. 113-143.

67 Palomares Peña, Propietarios norteamericanos y reforma agraria en Chibuabua, pp. 76-77. La visión agraria del gobernador Enríquez se basaba 
San Luis Potosí en 1922, cuando la idea de dividir los grandes latifundios enfrentó en el congreso local una feroz oposición que lo convenció de posponer la ejecución de la ley, una maniobra ante la cual Nieto no podía esperar ninguna ayuda del centro político. ${ }^{68}$ En Michoacán, el gobernador Francisco José Múgica, que ignoraba las órdenes de Obregón sobre la reforma de la pequeña propiedad y de los ejidos, fue destituido de su cargo en 1923 mediante un procedimiento de impugnación parlamentaria encabezado por seguidores de Obregón. ${ }^{69}$ En tanto, mientras Múgica seguía en su puesto, Obregón se valió del comandante militar de Michoacán, general Enrique Estrada, para evitar la implementación de la reforma, al tiempo que rechazaba por completo los reclamos del presidente del Comité Agrario Local en contra de Estrada y sus colegas que, a decir de él, llevaban "consigna de obstruccionar sistemáticamente el fraccionamiento de los latifundios y la dotación de ejidos de los pueblos rurales" ${ }^{70}$

principalmente en pequeños ranchos de familia aglutinados en colonias agrarias. Véase Domínguez Rascón, La política de la reforma agraria en Chibuabua, pp. 114-115.

68 FAlcón, Revolución y caciquismo, pp. 165-166.

69 Sánchez Díaz, La Revolución en Michoacán, pp. 112-117; SÁnchez Rodríguez, Grupos de poder y centralización política en México, pp. 211229; Oikión Solano, Los hombres del poder en Michoacán, p. 45 y notas 2-4; Ceballos Garibay, Francisco J. Múgica, p. 100; Guerra Manzo, “Los intermediarios políticos”, p. 85; BOYER, “Old Loves, New Loyalties”, pp. 432 438. Boyer y otros autores que no están familiarizados con el asunto parlamentario de 1921 y sus consecuencias atribuyen la renuncia (o despido) de Múgica a presiones ejercidas por la sociedad civil contra su radicalismo hiperbólico.

70 Presidente de la Comisión Local Agraria de Michoacán a Obregón (21 de noviembre de 1921); Secretario particular del Presidente de la República al presidente de la Comisión Local Agraria de Michoacán (5 de diciembre de 1921), AGN, Grupo documental Obregón-Calles. El presidente de la Comisión Local Agraria no era ingenuo. Al tiempo que le escribía al presidente Obregón que "de ninguna manera he querido creer o sugerir que de la Presidencia de la República emanen determinadas instrucciones que ponen en práctica las Autoridades Militares en el Estado...”, daba a entender que 
De un particular cinismo fue la respuesta de Obregón a Agustín Castro, gobernador de Durango, quien recurrió al presidente en noviembre de 1921 para solicitarle que abriera las puertas a la implementación de la ley agraria de su estado y promulgara una ley federal que permitiera a los estados establecer sus propias deudas agrarias. El gobernador Castro le explicó al presidente que la demanda de tierras en Hidalgo era particularmente alta debido a una notoria falta de categoría política de buena parte de las comunidades de su estado, lo cual les impedía recurrir a la “ley de enero de 1915", en sus palabras, la cual sólo atañía a pueblos reconocidos desde el punto de vista administrativo (es decir, político). A principios de diciembre, el presidente respondió al gobernador Castro, calificándolo de su "muy estimado y fino amigo", que en ese momento su administración estaba llevando a cabo "un estudio de toda nuestra Legislación Hacendaria con objeto de modificarla, prevaleciendo la intención de hacerla más liberal y menos complicada". "Al mismo tiempo", agregaba Obregón en su amistosa misiva,

[...] deseo expresarle la satisfacción que me causa saber que la base que usted está estableciendo en Durango para resolver la división de los latifundios está enteramente de acuerdo con la establecida por el Ejecutivo de mi cargo cuando hizo una exposición sobre el particular en la Cámara de Diputados antes de hacerme cargo del Poder. ${ }^{71}$

Ni una palabra se dijo en ese intercambio sobre el fiasco parlamentario de ese año, que involucraba seriamente a la delegación de Durango. La solicitud de Castro fue en vano, por supuesto.

sabía perfectamente que detener la reforma agraria en Michoacán era idea de Obregón, y no de Estrada.

${ }^{71}$ Carta de Agustín Castro a Obregón (18 de noviembre de 1921), AGN, Grupo documental Obregón-Calles, exp. 818-E-28 (1), Anexo I; Carta de Obregón a gobernador Agustín Castro (7 de diciembre de 1921), AGN, Grupo documental Obregón-Calles, exp. 818-E-28 (1), Anexo I. 
En diciembre de 1930, la liga agraria local notificaba al gobernador de Veracruz, Adalberto Tejada, que ni una sola de las pequeñas propiedades creadas con base en la ley de 1918 del exgobernador Cándido Aguilar en relación con el desmantelamiento de los latifundios había derivado en una escritura oficial. ${ }^{72}$ En mayo de 1932, el gobernador de Michoacán, Lázaro Cárdenas, declaraba en su informe anual a su parlamento local que

[...] no obstante el tiempo transcurrido desde la publicación de dichas Leyes [las leyes de expropiación de Michoacán de 1919 y 1920], en Michoacán no se ha verificado el fraccionamiento de los latifundios, ni los campesinos cuentan con las tierras necesarias para su sostenimiento y desarrollo y forman gran cantidad de personas y de familias que carecen de trabajo y de toda clase de medios de subsistencia. ${ }^{73}$

En mayo de 1934 fue aprobada una propuesta legislativa del diputado local Bernardo M. de León para la disolución directa de los latifundios de Nayarit, pero nunca fue implementada. ${ }^{74}$

Los estudios sobre el tema agrario a partir de la década de 1930 confirman estos hallazgos. Simpson, que estaba familiarizado con las leyes estatales sobre la disolución de los latifundios, no encontró pruebas (en 1933) al respecto en la práctica, salvo

72 Manuel Almanza, Presidente del Comité Ejecutivo de la Liga de Comunidades Agrarias, a Tejeda (2 de diciembre de 1930), en AGEV, Expediente de la iniciativa para el reglamento de la Ley para fomento de la pequeña propiedad, Fondo del Departamento de Agricultura y Ganadero, pq. 5070.

Sobre el estancamiento en Veracruz, e incluso la remoción de colonos que ya habían recibido parcelas privadas, véase Baitenmann, "Rural Agency and State Formation", p. 118; Ginzberg, "State Agrarianism versus Democratic Agrarianism", pp. 354-357.

73 "Anteproyecto de Decreto sobre Fraccionamiento de Latifundios y Fomento Agrícola", Periódico Oficial del Estado de Michoacán, t. 52, núm. 97 (23 mayo 1932), pp. 1-2.

${ }^{74}$ LeÓn, "La lucha por el exterminio del latifundio en Nayarit", p. 176. 
"muy pocos casos" que "han tenido un impacto práctico menor sobre el programa para la redistribución de la tierra". ${ }^{75}$ En 1964, Moisés de la Peña declaraba que "en la mayoría de los estados las publicaron para archivarlas [las leyes de pequeña propiedad]" ${ }^{76}$ En 1984, Romana Falcón, que -como sus predecesores- no menciona el episodio congresional de $1921,{ }^{77}$ explicó el fracaso de Nieto como resultado no sólo de la dura oposición de terratenientes poderosos, sino también de la repentina "suficiente sensibilidad política” de Obregón, gracias a la cual, "a contrapelo de las preferencias del 'grupo de Sonora', el ejido empezó a ser considerado como un fin en sí mismo". ${ }^{78}$ Todas las pruebas apuntan al hecho de que la orden de Obregón para detener cualquier acción agraria en la vía de la pequeña propiedad fue ampliamente obedecida, tanto durante su gobierno como durante los gobiernos que le siguieron. ${ }^{79}$ En 1933, Simpson describió la nueva situación creada en México, en consonancia con el enfoque de Obregón, como sigue:

Bajo el liderazgo de Obregón, México inició el largo y tortuoso camino de desgastar el sistema de los latifundios mediante los costosos y demorados métodos de la ley y el orden. México perdió su gran oportunidad de actuar cuando el fervor revolucionario aún estaba en su auge, con el resultado [...] de que ahora, casi 19 años después de la promulgación del decreto de 1915, la propiedad de la

75 Simpson, The Ejido, p. 71, nota 23.

${ }^{76}$ PeÑA, El pueblo y su tierra, p. 318.

77 Resulta sorprendente que el episodio parlamentario de 1921 brille por su ausencia en el detallado recuento de Womack sobre la actividad parlamentaria de los líderes y diputados del Partido Nacional Agrarista, los grandes defensores del proyecto de Obregón en la Cámara. Véase Woмack JR., Zapata and the Mexican Revolution, p. 510.

78 Falcón, Revolución y caciquismo, p. 166.

79 Véase, por ejemplo, WARMAN et al. (dir.), La transformación agraria, p. 53. 
tierra aún se concentra en buena medida en manos de unos cuantos privilegiados. ${ }^{80}$

Otros intentos por resucitar la iniciativa de Obregón, u otras similares, después de 1921, en forma de una iniciativa parlamentaria privada, o de una propuesta extraparlamentaria de agraristas preparados, como Molina Enríquez, Gilberto Fabila, Francisco Ursua, y el diputado y exgeneral zapatista Rafael Cal y Mayor, también fracasaron. ${ }^{81}$ De cuando en cuando, políticos famosos, como el senador de Michoacán Natalio Vázquez Pallares, acérrimo defensor del ejido, recordaban las olvidadas leyes de la pequeña propiedad (también conocidas como leyes agrarias) e intentaban resucitarlas, pero sin éxito. ${ }^{82}$ Las alternativas ofrecidas a los campesinos para que obtuvieran tierras privadas con base en la Ley de Tierra Libre de 1923 (denominada bomestead law en Simpson), la Ley Federal de Colonización de

80 Simpson, The Ejido, pp. 87-88, y nota 30, p. 88.

81 El 27 de diciembre de 1921, Molina Enríquez le escribió al presidente una larga carta en la que lamentaba que, en lugar de implementar la reforma agraria, tanto en su vertiente comunal (que definía como "acomodamiento de los pueblos”) como en la privada ("la de la pequeña propiedad”), México había tomado sólo la primera vía, poniendo así en peligro su futuro social y económico como un país fuerte y autosuficiente de clase media. Enríquez apuntaba que su postura, derivada de un involucramiento activo en el agrarismo mexicano durante los 30 años previos, estaba perfectamente fundamentada, y que por ello le encantaría presentársela al presidente en un seminario de cuatro horas que no tardaría en convocar. Obregón respondió amablemente que agradecía la generosa oferta, pero que no tenía tiempo para tomar un seminario. $\mathrm{Al}$ parecer, Obregón rechazó la propuesta de Enríquez no por falta de tiempo, sino porque no requería que Enríquez entendiera lo que México necesitaba. Lo que estaba en juego era distinto: mientras no pudiera garantizar el control federal del agrarismo defensor de la pequeña propiedad, prefería bloquearlo. Véase Carta de Andrés Molina Enríquez al presidente Álvaro Obregón (27 de diciembre de 1921); Carta de Álvaro Obregón a Andrés Molina Enríquez (9 de enero de 1922), ambas en AGN, Grupo documental Obregón-Calles, exp. 818-E-28 (1),

${ }^{82}$ Memoria del Senado de la República, p. 1300. 
1926 (revisada en 1946, derogada en 1962, e integrada al Código Agrario de 1942), ${ }^{83}$ e incluso la Ley de Patrimonio Ejidal de 1925 del presidente Plutarco Elías Calles (a medio camino entre la propiedad comunal y personal, todavía en el contexto del ejido), no tuvieron un gran impacto, sobre todo debido a la mala calidad de las tierras nacionales, su ubicación periférica y la enorme cantidad de recursos que debían invertirse en esas tierras para volverlas adecuadas para el trabajo agrícola, lo cual resultó ser el principal problema. ${ }^{84}$

\section{¿POR QUÉ SE PUSO FIN AL AGRARISMO \\ DEFENSOR DE LA PEQUEÑA PROPIEDAD EN MÉXICO?}

A primera vista, el ejido tenía claras ventajas en comparación con el sistema de la pequeña propiedad privada. En el nivel político, el ejido era más aceptable para los latifundistas, ${ }^{85}$ que tenían considerables intereses agrarios y minerales en México y cuyo

83 Reyes Osorio et al., Estructura agraria, pp. 695-703; Simpson, The Ejido, p. 86 , nota 26.

84 Ley de tierra libre para los mexicanos en México; Ley de 19 de diciembre de 1925 sobre repartición de tierras; Decreto por el cual todo mexicano mayor de 18 años tiene derecho a adquirir gratuitamente terrenos nacionales, México, Secretaría de Agricultura y Fomento, Dirección de Aguas y Colonización, 1930, pp. 241-242. Sobre el impacto dual de estas leyes, véase SÁNCHEZ GoNZÁLEZ, “El marco jurídico”, pp. 241-242.

85 El proceso para crear ejidos causó gran resentimiento entre los latifundistas. Sin embargo, su resentimiento respecto de las leyes estatales de la pequeña propiedad fue mucho más generalizado y derivó en amenazas implícitas de no invertir en sus activos, "pues desde el momento que las autoridades no consideran sagrada la propiedad, cesa toda confianza y se paraliza toda iniciativa”. Dichas amenazas apuntaban al daño económico ocasionado al país que, a decir de los latifundistas, ya sufría de una grave escasez de productos básicos y dependía cada vez más de la importación de bienes desde Estados Unidos. Véase Carta de la Cámara Nacional de Comercio, Industria y Minería del Estado de Nuevo León a Obregón (7 de enero de 1922). Véase también Carta de la Cámara Agrícola Nacional de Puebla a Obregón (22 de abril de 1922), ambas en AGN, Grupo documental Obregón-Calles, exp. 818-E-28 (1). 
reconocimiento de la Revolución era crucial para la estabilidad y el desarrollo económicos y políticos de México. ${ }^{86} \mathrm{El}$ sistema estaba protegido y supervisado tanto por el gobierno local como por el central, lo cual mantenía a sus beneficiarios bajo control y eternamente dependientes del apoyo del gobierno, sobre todo por su prolongado proceso regulador y su débil infraestructura. Ser socios de una gran iniciativa nacional brindaba a los campesinos una razón de ser, la sensación de formar parte de una larga saga heroica de la que algunos, o quizá muchos, aún tenían vívidos recuerdos como asociados o luchadores, o como sus descendientes ${ }^{87}$ Era un mecanismo eficiente para el entrenamiento político: desde el mismísimo punto de partida de la petición de tierra, hasta la creación de una estructura socioeconómica ejidal igualitaria y autoadministrada, sobre una base democrática.

La implementación del ejido era fácil de manipular, de acelerar o desacelerar, según las necesidades políticas del momento, como lo hizo incluso Cárdenas, el más destacado agrarista de todos los presidentes posrevolucionarios de México. ${ }^{88}$ Tenía una tremenda fuerza de reclutamiento político, de la que todos los candidatos a presidente $\mathrm{u}$ otros puestos políticos habían dependido desde el establecimiento de la Confederación $\mathrm{Na}-$ cional Agraria en 1923, hasta la fundación de la Confederación

86 Buchenau, The Last Caudillo, pp. 130-131; Meyer, "El primer tramo del camino", pp. 1218-1223.

87 Éste es el panorama general que encontramos en decenas de ejidos que estudiamos entre 1989 y 2014, a pesar de la multitud de problemas descritos por sus habitantes. Ésta es la situación que Simpson encontró en algunos de los ejidos que examinó en la década de 1920, y lo que Henrik Infield y Koka Freier vieron en 1952 durante una visita a 20 ejidos colectivos y parcelados. Véanse Simpson, The Ejido, pp. 306-315, 464-481; INFIELd y FreIER, People in Ejidos, pp. 30-31, 103-105, 129-141.

88 Meyer, "Los límites de la política cardenista", p. 7. Cárdenas, como gobernador de Michoacán, adoptó el mismo enfoque que el gobernador de Michoacán para allanar su camino hacia puestos políticos más elevados, quizá incluso la presidencia. Véase Ginzberg, Lázaro Cárdenas gobernador de Michoacán, pp. 173-175. 
Campesina Mexicana (сCM) en 1933 y de la Confederación Nacional Campesina (CNC) en 1938, cuyos miembros eran en su mayoría ejidatarios ${ }^{89} \mathrm{Su}$ popularidad no disminuyó ni siquiera cuando quedó de manifiesto que cientos de miles de solicitantes tenían que arreglárselas con el dudoso título de "beneficiados con derechos a salvo". En 1967, de un total de 2336000 beneficiados, 448000 solicitantes tuvieron que esperar pacientemente a que se descubriera un pedazo de tierra en algún lugar o que alguien dejara el ejido o muriera sin dejar herederos. ${ }^{90}$ Además, fortaleció al centro político de manera considerable al conferirle el poder que necesitaba para enfrentar retos en otros ámbitos, como el de las relaciones laborales, el desarrollo industrial, la implementación de la educación secular, la protección de los recursos minerales nacionales, las rebeliones contra el régimen, $\mathrm{o}$ la competencia con políticos que insistían en mantener el control aun cuando ya habían completado el periodo en su cargo. Uno de esos políticos fue el expresidente Plutarco Elías Calles (19241928), apodado "jefe máximo". 91

El sistema ejidal también tenía importantes ventajas económicas. Era fácilmente accesible para los campesinos debido a su gratuidad. Era un programa de costo relativamente bajo y fácil de regular, dado que los ejidos estaban ubicados en su mayoría en tierra fértil que podía volverse productiva en poco tiempo. Aspiraba a un cooperativismo avanzado dentro de cada comunidad y a nivel regional, tema especialmente crítico en lo tocante al uso de bosques, tierras de pastoreo, recursos acuíferos, créditos agrícolas y equipo tecnológico. Permitía la concentración de recursos sociales y tecnológicos en los niveles comunal e incluso regional y, en consecuencia, la reducción de los costos de inversión en estos ámbitos. Los ejidos, organizados con base

${ }^{89}$ Meyer, “El primer tramo del camino”, pp. 1207-1210, 1232-1236.

90 REYes Osorio, Estructura agraria, pp. 685-686.

91 Ginzberg, "El retorno de la ideología”, pp. 276-279. 
en una plataforma colectiva (de acuerdo con Salomón Eckstein había 934 ejidos de este tipo en 1940), ${ }^{92}$ eran supuestamente ideales en zonas de plantación industrial como Yucatán, La Laguna o Lombardía y Nueva Italia, y para proyectos complejos de desarrollo de infraestructura, como el Plan Chontalpa en Tabasco. ${ }^{93}$ Y, por último, era multigeneracional y flexible, sin duda mientras hubiera tierras disponibles para la expropiación y la ampliación.

Desde la perspectiva del centro político, las pequeñas propiedades privadas sólo tenían desventajas. Conllevaban confrontaciones directas con el latifundismo, lo cual podía originar una feroz oposición por parte de los latifundistas, e incluso podía empujarlos a recurrir a la presión extranjera sobre el tema. ${ }^{94}$ Confería un poder considerable a los estados y al Congreso nacional respecto del centro político. En teoría, su implementación sería relativamente rápida -una o dos generaciones a lo mucho-, algo que podía hacerlas difíciles de manipular con el

92 Eckstein, El ejido colectivo en México, cuadro 7, p. 173.

93 Arrieta Fernández, La integración social de la Chontalpa; Martínez Assad, Breve historia de Tabasco, cap. VI.

${ }^{94} \mathrm{La}$ inquietud de que la confrontación con los latifundios pudiera generar oposición interna y externa, en específico oposición por parte de Estados Unidos, quedó claramente de manifiesto con la introducción de una detallada cláusula penal en la iniciativa, algo que nunca se había incluido en la legislación ejidal. Entre otras cosas, el artículo 46 de la iniciativa apuntaba: "Los que con el objeto indicado provoquen la intervención extranjera o que en cualquier forma busquen el apoyo de los gobiernos o de los pueblos extraños para que ejerzan presión diplomática, militar o económica sobre el pueblo o Gobierno de México, quedarán privados de su calidad de ciudadanos y pagarán una multa de igual valor del cuarenta por ciento de sus bienes". Cuando las discusiones en torno al artículo 46 dieron inicio de manera oficial a fines de junio, el diputado José Siurob declaró que sabía de "hechos enteramente concretos" sobre movimientos subversivos por parte de los latifundistas, que "tratan de provocar una intervención de los Estados Unidos en México", con el fin de frustrar el proyecto de fraccionamiento. Véase Ley de fraccionamiento de latifundios, 20 de junio de 1921, p. 19. 
tiempo. ${ }^{95}$ Las dimensiones y clasificaciones diferían de un estado a otro y, en algunos casos, como en Chihuahua, Coahuila, Querétaro, Durango y Sonora, el proceso no estaba lejos de ser un tipo de neolatifundismo. ${ }^{96}$ Algunos informes de zonas donde este sistema se había practicado indicaban que los campesinos lo preferían a la opción ejidal. ${ }^{97} \mathrm{Su}$ popularidad cuestionaba la implementación y el avance de la reforma ejidal, en especial cuando ambos sistemas resultaban estar vinculados con las mismas tierras cultivables, y por ende limitaban el alcance de la presencia federal en el ámbito agrario. A decir verdad, podía crear una clase de agricultores independientes y adinerados con tendencias conservadoras, que no necesariamente se apegarían a los caprichos del Estado revolucionario, ni se unirían a sus organizaciones locales y nacionales basadas en el poder popular, con lo cual debilitarían el régimen central y su poder de negociación en todos los niveles. ${ }^{98}$

95 A decir de Siurob, el reparto de latifundios podía concluirse en una generación (supongo que quería decir 20 años), aunque personalmente recomendaba extenderlo a lo largo de dos generaciones para darle a los latifundistas que habían comenzado a erigir sistemas de riego extensivos, tiempo suficiente para completar su proyecto. Véase Ley de fraccionamiento de latifundios, 30 de mayo de 1921, p. 23.

96 Tannenbaum, The Mexican Agrarian Revolution, pp. 434-435; Fabila y UrsúA, Fraccionamiento de latifundios, pp. 56-57.

97 Véase el típico caso yucateco en McCutchen McBride, The Land Systems of Mexico, p. 169. Ann Craig argumenta que el deseo básico de los colonos en Lagos de Moreno (región de Los Altos, estado de Jalisco) era obtener pequeñas propiedades. Sin embargo, acabaron por aceptar el sistema ejidal debido a las presiones y amenazas que sufrieron por parte de propietarios de fincas, curas y cristeros (soldados católicos de Cristo), y al simple hecho de que en realidad no había otra forma de obtener tierras más allá de lo que ofrecían los agentes estatales. Véase Craig, The First Agraristas, pp. 125-127, 179-200.

98 "En México, como en otras partes”, dice Alan Knight, "los campesinados posteriores a la reforma tendieron a cultivar sus propios jardines [luego de que] el impulso de la movilización se disipara [y los radicales menos apasionados de antaño] se convirtieran en los pequeños agricultores (relativamente) inactivos de la época post-Reforma, propensos a las alianzas clientelistas con el Estado 
El proyecto de la pequeña propiedad privada también podría haber tenido varios inconvenientes económicos. Si no se llevaba a cabo con suficiente cuidado, podía afectar a latifundios eficientes y causar graves daños económicos. Puesto que los beneficiarios debían pagar por la tierra, resultaba menos accesible para los campesinos, que temían enfrentar dificultades financieras y perder sus tierras. La reforma de la pequeña propiedad dependía de la deuda agraria de los estados, que apenas había sido autorizada por el Congreso federal en enero de 1925, con una cantidad inicial relativamente limitada. ${ }^{99}$ En pocas palabras, los estados difícilmente podían argumentar que tenían los recursos suficientes para administrar reformas de la pequeña propiedad a tan gran escala.

También había un grave problema de amparos en materia agraria, que sólo un congreso comprometido y respaldado por un gobierno central decidido podía enfrentar, como terminó haciéndolo en el ámbito ejidal en diciembre de $1931 .{ }^{100}$ De otra forma, no se lograría nada, como ocurrió en Veracruz con Tejeda, cuando las interminables deliberaciones judiciales sobre la legalidad de la expropiación y la división de los latifundios no pudieron resolverse. En resumen, esta reforma particular, que parecía tan clara y efectiva, se convertiría en un calvario financiero, legal y judicial mientras el centro político permaneciera fuera de escena.

Sin embargo, si bien éste parecía ser el caso, tal vez había razones de mayor peso para que el México oficial prefiriera

en expansión”. Véase KNighT, "Popular Culture and the Revolutionary State", p. 440. Esto es lo que ocurrió en Veracruz, donde algunos ejidatarios no dudaron en unirse a la Mano Negra, la violenta organización antiagrarista de Manuel Parra, dueño de la hacienda Almolonga. Véase SKERRITt Gardner, “Qué es la Mano Negra”, pp. 129-138.

99 Luna Arroyo y Alcerreca (eds.), Diccionario de derecho agrario, p. 229; "Reglamento de la expedición y amortización”, pp. 232-237.

100 Luna Arroyo y Alcerreca (eds.), Diccionario de derecho agrario, p. 30. 
renunciar a la solución de la pequeña propiedad y se enfocara esencialmente en la solución del ejido. Antes de pasar a ellas y resumir nuestros hallazgos, nos gustaría examinar algunos de los supuestos básicos relacionados con el ejido en México y el campesinado mexicano, que estaba atrapado en una larga disputa en torno al proyecto ejidal. La disputa terminó oficialmente en presencia de y con el consenso de los representantes de hasta 100 organizaciones campesinas, convocadas por el presidente Carlos Salinas de Gortari en Los Pinos en noviembre de 1991. Las afirmaciones de los defensores del ejido en torno al apoyo popular supuestamente amplio del sistema y su capacidad de detener el neolatifundismo, junto con los argumentos de que los campesinos mexicanos no podían con los desafíos personales planteados por la pequeña propiedad, deben verse con escepticismo. ${ }^{101}$ La capacidad del campesino mexicano para adaptarse a la agricultura privada se discutió en profundidad en la atmósfera extremadamente tensa de las deliberaciones parlamentarias de 1921. Ante los argumentos que enfatizaban la naturaleza "primitiva” del campesino mexicano, ${ }^{102}$ muchos diputados apoyaron el planteamiento contrario. Citando a Antonio Díaz Soto y Gama (quien, como exzapatista, claramente reflejaba las opiniones de su líder) durante una discusión sobre el tema de la cooperación, el 31 de mayo de 1921, Emilio Gandarilla, de Durango, describió la situación como sigue:

El campesino en general está enamorado de la tierra en forma de pequeña propiedad [...] En México existe ese mismo amor a la tierra. ¿Qué hombre más representativo de la clase campesina me dan ustedes que Emiliano Zapata? Pues bien; el jefe Zapata, en conversación que tuvo con un muchacho de ideas avanzadas [...]

101 Esto es lo que Luis Cabrera afirmó insistentemente a lo largo de los años. URREA, Veinte años después, p. 272.

102 Véase la controversia sobre este tema en Ley de fraccionamiento de los latifundios, 3 de mayo de 1921, pp. 10-11. 
en Yautepec, recién llegado yo a la revolución en 1915, es decir, a fin de 1914 [...] se llegó a plantear al jefe Zapata la cuestión de si debía ser la tierra dividida en pequeñas propiedades o establecerse el comunismo, y él enérgicamente contestó, con toda su psicología de campesino, contra el comunismo. Dijo en términos rancheros: “ Un demonio! ¡Yo quiero mi pedazo de tierra para mí!” Ese es el culto del campesino, esmerarse en el cultivo de su parcela y sacar de su parcela todo lo que la parcela rinda para sí, exclusivamente para sí. El que quiera ir contra la tendencia del campesino, no conoce al campesino, no conoce en realidad al campesino, y se coloca fuera del terreno y de la práctica. ${ }^{103}$

A decir verdad, la opinión de los agraristas de que los campesinos mexicanos preferían el sistema ejidal por sobre todos los demás arreglos no tenía fundamento. Buena parte de las pruebas recogidas del discurso mexicano sobre el agrarismo -y apoyadas por académicos, militares, estadistas, legisladores, investigadores y agrónomos de varias generaciones y perspectivas- apuntaban al hecho de que los campesinos mexicanos, fueran de origen indígena o mestizo, preferían el modelo de la pequeña propiedad y la libertad de acción que éste conllevaba. ${ }^{104}$ También ésta fue la opinión de buena parte de los gobernadores militares durante la época revolucionaria y, después, de los

${ }_{103}$ Ley de fraccionamiento de latifundios, 30 de mayo de 1921, pp. 23-24, y 15 de junio de 1921, pp. 13-14.

104 En este contexto, Alan Knight afirma lo siguiente: "La noción de que el campesinado mexicano en general se aferrara a la tenencia comunal de la tierra, una derivación quizá del calpullali azteca, me parece muy exagerada”. Knight, "Land and Society", p. 86. El individualismo agrícola era naturalmente característico de muchos agricultores que rechazaban el ejido por razones ideológicas, morales o prácticas. Véanse KNigHT, "Land and Society”, pp. 8586; Baitenmann, "Rural Agency and State Formation”, pp. 404-409; Falcón, Revolución y caciquismo, p. 173; Purnell, Popular Movements and State Formation, pp. 9-10, 153-157, 181-183; SALAS LANDA, "Enacting Agrarian Law", pp. 700-714. 
gobernadores civiles, como lo demuestran sus acciones, legislaciones y declaraciones. Esto se ve claramente reflejado en un informe de 1922 al Congreso por parte del gobernador de Durango, Agustín Castro: "los ejidos no dan resultado por no darse la parcela en propiedad individual". ${ }^{105}$

La postura de los líderes de la convención, Emiliano Zapata y Francisco Villa, que desde un principio habían abordado el tema agrario de manera totalmente pragmática, también contradecía las afirmaciones de los defensores del ejido. ${ }^{106}$ Esta postura la defendía una (tenue) mayoría respecto al artículo 20 de la ley de Obregón de 1921, que definía el tipo de propiedad que estaría disponible al concluirse el proceso de adquisición. Miles de braceros locales y repatriados que habían regresado a México de Estados Unidos adoptaron una postura similar, como lo muestran los debates de 1921 y lo examina en profundidad Ann Craig. ${ }^{107}$

105 PeÑA, El pueblo y su tierra, p. 317.

106 En este sentido, Zapata y el secretario de Agricultura de la convención, Manuel Palafox, dejaron la cuestión del reparto agrario a la libre decisión interna de cada comunidad restaurada. Véanse Woмack Jr., Zapata and the Mexican Revolution, pp. 318, 325; Brunk, Emiliano Zapata, pp. 149-150; CóRdova, La ideología de la Revolución Mexicana, pp. 144-145, 159. En una de sus declaraciones en torno al tema agrario, Zapata escribió: "No socialización, no colectivización. Tierra libre, parcela libre. Libre cultivo, libre explotación de la parcela. Sin capataces y sin amos dentro del ejido [...] pero también sin tiranías ejercidas por el Estado o por la colectividad”. En CóRDova, La ideología de la Revolución Mexicana, pp. 154-155. El enfoque individualista de Zapata quedó aún más claro en sus declaraciones públicas y decretos agrarios. Véase Arboleyda Castro, El nacimiento del ejido moderno, pp. 64-66. Pancho Villa no pensó en ninguna opción agraria distinta a la particular. Desde su proclama en diciembre de 1913 sobre la futura distribución de la tierra a los campesinos tras la victoria final y hasta su ley agraria de mayo de 1915, el principio siguió siendo el mismo: confiscar los latifundios y dividir la tierra en parcelas de familia de hasta 25 hectáreas de tierra cultivada, otorgándolas de manera gratuita a todos los agricultores sin tierras, y dando prioridad a los más pobres. Véase KaTz, The Life and Times of Pancho Villa, pp. 359, 408-413.

107 Ley de fraccionamiento de latifundios, 30 de mayo de 1921, p. 19; Craig, The First Agraristas, pp. 179-184. 
Unos antropólogos estadounidenses del Smithsonian revelaron este mismo acercamiento firmemente individualista a la tierra al estudiar las complejas formas de vida de los tarascos en la década de 1940, acercamiento que se cree comenzó a desarrollarse tras la reforma de Sebastián Lerdo de Tejada. ${ }^{108}$

¿Podría la ley de la pequeña propiedad haber obstaculizado la compra de tierras por parte de los campesinos pobres en México? Es muy poco probable. Si bien podrían haber evitado, hasta cierto punto, que los campesinos poco dedicados "compitieran" por tierras, en la mayoría de los estados, las leyes de pequeña propiedad estaban, por definición, dirigidas a la gente pobre -peones, jornaleros, aparceros, arrendatarios- $\mathrm{o}$, como lo describe la ley de Durango: "con beneplácito sincero de parte de todas las clases sociales, absolutamente de todas, de aquella Entidad Federativa”. Fue en este tenor que se llevaron a cabo las deliberaciones de $1921 .{ }^{109}$ También fue éste el estado de ánimo que precipitó la redacción de buena parte de las leyes estatales aprobadas entre 1915 y $1927 .{ }^{110}$ También fue la esencia

108 Beals, Cherán. A Sierra Tarascan Village, pp. 23, 59; West, Cultural Geography of the Modern Tarascan Area, p. 32; Foster, Empire's Children, pp. 171-172.

${ }_{109}$ El debate en torno a las preguntas sobre quiénes recibirían parcelas de familia obtuvo decenas de respuestas. Todos hablaron en repetidas ocasiones sobre los peones del campo, braceros, jornaleros, medieros, aparceros y arrendatarios. El artículo 15 de la propuesta estipulaba: "Entre los vecinos del lugar tendrán derecho preferente los arrendatarios, medieros y peones de las tierras que se fraccionen". Ley de fraccionamiento de latifundios, 7 de abril de 1921, p. 9. Sobre la ley de Durango, véase la sesión del 1o de agosto de 1921.

${ }_{110}$ En 1916, Salvador Alvarado escribió una introducción a su ley agraria: "Sólo creando, así, la pequeña propiedad, podremos robustecer a nuestro pueblo, arrancándolo de las garras del proletariado que tiende siempre a debilitar a los pueblos, cuando no hay raíces fuertes y ramificadas en la tierra por medio de apego a ella...”. Véase Alvarado, A dónde vamos, pp. 9-10. En las deliberaciones legislativas de 1919 sobre el establecimiento de un fondo de deuda que permitiera la expropiación de los latifundios, de acuerdo con la ley 45, el diputado Antonio Mayés Navarro dijo lo siguiente: “ambas Leyes [la ley ejidal 
de los mensajes enviados al Senado a fines de 1921 por varias juntas agrarias del país, que habían rastreado los procesos parlamentarios para legislar el ejido y la pequeña propiedad, incorporándolos en un formato conceptual que declaraba:

Las leyes de ejidos y de fraccionamiento de latifundios, aprobadas por la Cámara de Diputados el presente año, constituyen la más grande de las conquistas realizadas por la Revolución Mexicana y vienen a señalar un trascendental paso a la vida de la República, dando oportunidad a la raza indígena, mediante su trabajo y asiduidad, para lograr su liberación económica, de que gozaba antes de la dominación española; libertad complementaria de la libertad política alcanzada por el país al hacer su independencia; pero que no ha llegado aún hasta la raza indígena, supeditada a los herederos de los conquistadores y privada de toda iniciativa. ${ }^{11}$

Las razones para desistir del modelo mexicano de pequeña propiedad deben, por ende, encontrarse en otro lado. El México posrevolucionario estaba buscando políticas que combinaran la estabilidad y la legitimidad políticas con medidas dirigidas a construir una nación y un Estado basados en la justicia social. Tal combinación se adhería a buena parte de los

y la ley de fraccionamiento de los latifundios, E. G.] no tenían más objeto que facilitar la creación de la pequeña propiedad. Porque si las dotaciones agrarias resolvían el problema del campesino pobre, había otros que tenían algún recurso, algún derecho, y no cabrían en las reparticiones ejidales, y éstos eran los que se encontraban sujetos al sistema de medieros y aparceros y a quienes se podía quitar de esa condición elevándolos a la categoría de propietarios mediante la aprobación de la Ley a debate". Véase Acta número 79, sesión del día 12 de marzo de 1919, en Actas de sesiones de la XXXVII Legislatura del estado, 13 de septiembre de 1918-15 de marzo de 1919, folio 3, exp. 1, c. 41, fondo Legislatura, serie Actas públicas, periodo 13 de septiembre de 1918, final: 10 de marzo de 1919, pp. 6-7.

111 Véase, por ejemplo, Diario de los debates de la Cámara de Diputados del Congreso de los Estados Unidos Mexicanos, Legislatura XXIX, año II, t. III, núm. 26, 9 de noviembre de 1921, pp. 7-8. 
"genes" ideológicos de la Revolución, formulados y moldeados durante el conflicto armado. ${ }^{112}$ Estos objetivos podían alcanzarse idealmente mediante acciones reformistas moderadas y "equilibradas". ${ }^{113}$ Así, aunque algunos miembros de las primeras generaciones de este liderazgo, en particular el grupo de Sonora, prefirieran la pequeña propiedad privada, evidentemente sospechaban que mientras este tipo de agrarismo no se volviera una prerrogativa federal-sobre todo en lo tocante a su alcance y su miríada de implicaciones nacionales, como lo expusieron con claridad los comités agrarios de la Cámara de Diputados durante el debate de 1921-, su naturaleza misma amenazaría los enfoques moderados. Es por ello que Obregón perdió interés en su propuesta, derrotada en julio de 1921. También a ello podría deberse que su sucesor, Calles, que no quería otro fracaso en el Congreso, haya ignorado la propuesta renovada presentada en 1925 por los diputados federales Gilberto Fabila y Francisco Ursúa, y prefiriera lo que consideraba (de manera errónea) "la salida más segura": el "patrimonio parcelario ejidal”. Éste sustituiría al ejido nominal (y legalmente) corporativo -que Calles consideraba "haría nugatorio el esfuerzo para la reconstrucción económica del país", como lo dijo el 2 de septiembre de 1925 en la Cámara de Diputados- ${ }^{114}$ y brindaría a los campesinos un pedazo de tierra privada protegido, el tipo de propiedad "necesarísima para despertar el interés del campesino en el cultivo y aumento de producción de las tierras, así como ese arraigo del mismo campesino a la parcela". ${ }^{115}$

112 Sobre el desafiante concepto "genético" de la Revolución mexicana, véase KNIGHT, “The Ideology of the Mexican Revolution”, pp. 77-109.

113 Tello, La tenencia de la tierra en México, p. 82.

114 Medin, Ideología y praxis política de Lázaro Cárdenas, p. 155; Diario de los debates de la Cámara de Diputados, Legislatura XXXI, año II, periodo ordinario, sesión del 2 de septiembre de 1925, en http://cronica.diputados.gob. $\mathrm{mx} / \mathrm{DD}$ ebates/31/2do/Ord/19250902.html.

115 Diario de los debates de la Cámara de Diputados, Legislatura XXXI, 2 de septiembre de 1925. 
El 15 de junio de 1930, cuando Calles comprendió que el modelo que había creado tenía una recepción desfavorable entre los campesinos, sobre todo porque en ese momento todos los ejidos eran de hecho "parcelarios" (es decir, se cultivaban de manera individual) y "patrimoniales", aunque ejidos al fin y al cabo, ${ }^{116}$ difundió la siguiente y muy conocida declaración, publicada un día después en El Universal: "Si queremos ser sinceros con nosotros mismos, tenemos la obligación de confesar, los hijos de la Revolución, que el agrarismo, tal y como lo hemos entendido y practicado hasta ahora, es un fracaso". ${ }^{117}$

No obstante, es probable que la reforma de la pequeña propiedad fuera suspendida debido a otras razones esenciales. Primero, la renuencia del centro federal a modificar el artículo 27 de la Constitución, una enmienda que podía transferir al centro la responsabilidad de esta reforma. Este cambio habría originado graves confrontaciones con los estados federados, algo que algunos diputados, como Uriel Avilés, ya habían advertido al gobierno central, invocando el peligro de una nueva revolución si dicha reforma se llevaba a cabo. La segunda razón era la posibilidad de utilizar tierras federales libres e implementar las leyes de colonización de manera efectiva explotando la riqueza de los territorios nacionales dispersa a lo largo y ancho del país, aun cuando se requirieran grandes inversiones, en especial en proyectos de irrigación. Esto de hecho ocurrió durante y después del gobierno de Ávila Camacho, y en cierta forma incluso antes. ${ }^{118}$ Una tercera razón fue el ímpetu que el libre mercado

116 En este contexto, véanse los artículos 16-17, 20-24 y 31 de la circular 48 del 1ㅇ de septiembre de 1921, relativos a la parcelación de tierras agrícolas del ejido en propiedades de familia, en contraposición a las pasturas y el bosque, designados para el uso común, en FABILA, Cinco siglos de legislación agraria, pp. 375-378.

117 El Universal (16 jun. 1930); Medin, El minimato presidencial, pp. 101-102. 118 El 8 de abril de 1938, el gobierno emitió un decreto especial que permitía a todos aquellos que hubieran adquirido tierras estatales a compañías deslindadoras obtener su título de propiedad, como lo estipulaba la Ley de Tierras 
de bienes raíces introdujo en el ámbito agrario, generando una reforma agraria informal de facto. Dentro de este mercado, no sólo los campesinos no ejidales encontraron tierras propias, sino también un gran número de ejidatarios, que compraron parcelas adicionales y las agregaron a sus pequeñas parcelas ejidales, con lo cual se convirtieron de hecho en "pequeños propietarios" o agricultores. ${ }^{119} \mathrm{Y}$, por último, la cuarta razón fue que desde la rápida renovación del reparto agrario por parte de Cárdenas -que además lo elevó al nivel de ethos y piedra angular de la Revolución-, ${ }^{120}$ todos los presidentes mexicanos entendieron que el marco del ejido no era adecuado para todos los sectores: a los ganaderos y a la gente pobre, cuya forma de vida les dificultaba organizarse como núcleos ejidales, debían ofre-

\footnotetext{
Libres del 2 de agosto de 1923. El decreto rescató a 23037 titulares de 3.9 millones de hectáreas. Véase Cárdenas, Seis años de gobierno al servicio de México, p. 116. Para profundizar en este tema, véanse Gutelman, Capitalismo y reforma agraria en México, pp. 112-121; IBARRA MENDIBIL, Ejido y control estatal, p. 22; Padilla Calderón, Agua, poder y escasez, pp. 170-171; WARMAN et al., La transformación agraria, pp. 62-63; HeWITT DE AlCÁNTARA, La modernización de la agricultura mexicana, pp. 173-174, 290-292; Medin, El sexenio alemanista, pp. 123-132; REYEs OsORIO et al., Estructura agraria, pp. 695-703. Entre 1926 y 1962, se erigieron 1240 colonias en siete millones de hectáreas para 61146 familias, que comprendían un total de 370000 personas. Véase REYes Osorio et al., Estructura agraria, p. 700. La mala calidad de las tierras nacionales se discutió ampliamente en el debate de 1921, en relación con el artículo 18 de la iniciativa. Véase Ley de fraccionamiento de latifundios, 18 de abril de 1921.

119 Este hecho se deduce del considerable aumento de tierras explotadas por particulares entre 1940 y 1960, y del aumento paralelo de la población ejidal durante el mismo periodo. Véase REYEs Osorio et al., Estructura agraria, pp. 54-58. Por otro lado, existía el fenómeno bien conocido de los no pocos particulares que rentaban o incluso "compraban" tierras ejidales.

120 Véanse, por ejemplo, "Palabras del Gobernador Constitucional del Edo. de Michoacán al inaugurar el Instituto de Investigaciones Sociales", 6 de noviembre de 1930, en CÁrdenas, Palabras y documentos, pp. 91-93; "Discurso del Presidente del PNR sobre el programa de trabajo para el año de 1931", 31 de diciembre de 1931, en Cárdenas, Palabras y documentos, pp. 98-101, pp. 98-101.
} 
cérseles arreglos alternativos. Estos arreglos tomaron la forma de concesiones especiales otorgadas a los ganaderos durante un periodo de 25 años, ${ }^{121} \mathrm{y}$ asignaciones de tierra a los paracaidistas cerca de las cuencas de desagüe o en otros sitios remotos. ${ }^{122}$ Es muy posible que estas razones -en especial las alternativas formales e informales ofrecidas a los campesinos privados a lo largo de los años, así como el lapso cada vez mayor transcurrido desde las discusiones iniciales de 1921, por más interesantes e intelectualmente asombrosas que hayan sido, aunque inútiles en la práctica- desviaran la atención de lo que se conocía como el "ideal revolucionario agrario".

\section{CONCLUSIÓN}

Existe una aceptación general sobre el éxito que tuvo el México posrevolucionario al estabilizar al país y colocarlo en una posición más firme. ${ }^{123}$ Sin embargo, considerando las enormes adversidades que sufrió el campo mexicano, resulta difícil tener una impresión favorable de dicho éxito. En el análisis final, México temía una reforma agraria rápida y eficiente que fuera llevada a cabo por sus estados federados o en cooperación con ellos. En medio de las rivalidades ideológicas y el bagaje emocional heredado por la reciente guerra civil, ni siquiera los diputados de la XXIX Legislatura lograron establecer dicho arreglo. A fin de cuentas, se estableció una reforma centralizada, paternalista y limitada. De acuerdo con Pablo González Casanova, muchos años antes de que la reforma ejidal concluyera oficial-

121 CÁrdenas, Seis años de gobierno al servicio de México, pp. 207-210; “Decreto que adiciona el Código Agrario de los Estados Unidos Mexicanos”, en Fabila, Cinco siglos, pp. 633-635.

122 El 19 de septiembre de 1939, Cárdenas otorgó la propiedad de 53662 hectáreas a 20453 paracaidistas y campesinos estacionales. Véase Cárdenas, Seis años de gobierno al servicio de México, p. 118.

123 González Casanova, La democracia en México, p. 85. 
mente (en la década de 1960), entre 50 y 70\% de la población mexicana (de la cual $47 \%$ eran habitantes rurales) tenía una forma de vida marginal, ${ }^{124}$ caracterizada por la pobreza (33\% de la población nacional según James Wilkie), ${ }^{125}$ el analfabetismo (52\% de la población rural), la dependencia y la explotación, una migración interna y emigración masivas, la indiferencia política y el autoritarismo, el minifundismo, la desnutrición (51\% de la población rural), ingresos continuamente a la baja (desde 1940) y la discriminación étnica y regional. ${ }^{126}$

Otro aspecto negativo de esta realidad es que no era (o no debería haber sido) una sorpresa para nadie. La mayoría de los observadores agrarios destacados -empezando por el mismo Calles en 1930 (“ni una palabra más sobre el particular”), y siguiendo con Luis Cabrera en 1931 ("El tercer vicio consiste en haber tomado la dotación de ejidos como el fin y no como el medio”), Alfonso Goldschmidt en 1940, Ramón Fernández y Fernández en 1953 y en años posteriores, Antonio Díaz Soto y Gama en 1959, Moisés de la Peña en 1963, Marco Antonio Durán en 1965, Sergio Reyes Osorio y su equipo en 1974, no pocos investigadores contemporáneos, e incluso Carlos Fuentes en $\mathrm{La}$ muerte de Artemio Cruz (1962), con su sarcasmo y creciente frustración-127 advirtieron sobre el peligro de consolidar una

124 González Casanova, La democracia en México, p. 175.

125 Wilkie, La revolución mexicana, cuadro IX, p. 268. De acuerdo con el Banco Mundial, la línea de pobreza extrema se encuentra actualmente en 1.9 dólares diarios per cápita, o 9.5 dólares diarios por familia de cinco. En 1960, la línea de pobreza era de 1.13 dólares diarios por familia. De acuerdo con los datos presentados por Casanova, 73\% de las familias rurales de México ganaba menos de 1.33 dólares diarios en 1962, y 45.5\% de las familias rurales ganaba menos de 0.8 dólares (10 pesos) al día. Véase González Casanova, La democracia en México, cuadro LXV, p. 327.

126 González Casanova, La democracia en México, pp. 90-98, 115-124, 136, 153-160, 165, 272-273, 327-328.

127 En La muerte de Artemio Cruz, Fuentes describe claramente el alcance del desastre agrario. Cruz, un exrevolucionario que queda a cargo de la gran propiedad (y de la hija) de don Gamaliel, comprende que su única opción 
gran aventura agraria sobre los endebles hombros de los ejidos, que además debían cargar con expectativas cooperativistas y colectivistas de largo alcance. En un principio, el ejido fue visto como una entidad transitoria y no como un ideal duradero de la pequeña propiedad en México, una lógica presentada con gran claridad por Luis Cabrera en su Balance de la Revolución el 30 de enero de 1931 en la Biblioteca Nacional: "es imposible que se consolide la institución del ejido si no hay agricultores".

En 1977, Lorenzo Meyer escribió que “en 1917, México produjo uno de los conjuntos de reglas políticas más avanzados del momento, pero la materia prima de la democracia aún estaba ausente. Quizá el tiempo perdido no podría recuperarse. La Revolución, en su lucha por la supervivencia, no tuvo tiempo de crear las precondiciones sociales y políticas necesarias para la democracia”. ${ }^{128}$ En nuestra opinión, la "materia prima de la democracia” sí prevaleció. Sin embargo, aunque ésta debía hacerse patente en el proyecto de la pequeña propiedad, fue relegada, no sólo porque la Revolución estaba luchando por sobrevivir y necesitaba grupos de campesinos que se alistaran en su construcción del poder, sino también porque la política mexicana posrevolucionaria había adoptado estructuras de pensamiento y acción autoritarias, con las que estaba tradicionalmente familiarizada, y rechazado formas federalistas de pensar, que el proyecto de la pequeña propiedad, o más bien el bienestar

es dividir el latifundio que recibió en pequeñas parcelas de tierra de cultivo (probablemente tierras ejidales). Ante esto, Cruz no se muestra preocupado, sino realista, como le explica a su suegro: "No se puede detener el curso de las cosas. Vamos entregándole esas tierras a los campesinos, que al fin son tierras de temporal y les rendirán muy poco. Vamos parcelándolas para que sólo puedan sembrar cultivos menores. Ya verá usted que en cuanto tengan que agradecernos eso, dejarán a las mujeres encargadas de las tierras malas y volverán a trabajar nuestras tierras fértiles. Mire no más: si hasta puede usted pasar por un héroe de la reforma agraria, sin que le cueste nada". Véase FuENTES, $L a$ muerte de Artemio Cruz, pp. 59-60.

128 Meyer, "Historical Roots of the Authoritarian State in Mexico", p. 19. 
de México, necesitaba con tanta urgencia. Cuando el presidente Salinas de Gortari por fin descubrió lo que a México en verdad le faltaba -comunidades agrarias familiares independientes, libres de frenos gubernamentales-, ${ }^{129}$ era demasiado tarde. ${ }^{130} \mathrm{Su}$ momento óptimo había sido a principios de la década de 1920, o quizá entre 1935 y 1940, cuando el Estado era lo bastante fuerte y decidido para definir sus objetivos agrarios. La pobreza y negligencia padecidas por tantas regiones agrícolas y por la gente que aún las habitaba, fueron testimonios silenciosos de las oportunidades perdidas. Revertir los desiguales arreglos de propiedad arraigados en la economía nacional y establecer nuevas prioridades podría haber hecho de México un país liberado y más próspero.

\section{SIGLAS Y REFERENCIAS}

AGN Archivo General de la Nación, Ciudad de México, México

AGEV Archivo General del Estado de Veracruz, Veracruz, México

Alvarado, Salvador, $A$ dónde vamos: las cinco hermanas, Mérida, Yucatán, Imprenta "El Modelo", 1916.

Arboleyda Castro, Ruth E., El nacimiento del ejido moderno: la ley de ejidos de 1920, México, El Colegio de México, 1998.

Arrieta Fernández, Pedro, La integración social de la Chontalpa: un análisis regional en el trópico mexicano, México, Universidad Iberoamericana, Gernika, 1994.

Baitenmann, Helga, "Rural Agency and State Formation in Post-revolutionary Mexico: Agrarian Reform in Central Veracruz (1915-1992)", tesis doctoral, Nueva York, New School for Social Research, 1997.

Bartra, Armando, “A Persistent Rural Leviathan”, en Randall, 1996, pp. 173-184.

129 Bartra, “A Persistant Rural Leviathan”, pp. 173-184, en especial p. 174.

130 WARMAN et al. (dirs.), La transformación agraria, p. 86. 
Bassols, Narciso, El pensamiento político de Álvaro Obregón, México, Ediciones El Caballito, 1976.

Beals, Ralph L., Cherán, A Sierra Tarascan Village, Norman, University of Oklahoma Press, 1998.

Benítez Salazar, Felipe de Jesús et al. (comp.), Lázaro Cárdenas: modelo y legado, México, Instituto Nacional de Estudios Históricos de las Revoluciones de México, 2009.

Bonilla, Manuel, Apuntes para el estudio del problema agrario, Hermosillo, Sonora, Imprenta del Gobierno del Estado, 1914, en Silva Herzog (ed.), 1961, t. III, pp. 237-287.

Boyer, Christopher R., "Old Loves, New Loyalties: Agrarismo in Michoacán, 1920-1928”, en The Hispanic American Historical Review, 78: 3 (ago. 1998), pp. 419-455.

Brunk, Samuel, Emiliano Zapata. Revolution and Betrayal in Mexico, Albuquerque, Nuevo México, University of New Mexico Press, 1996.

Buchenau, Jürgen, The Last Caudillo. Álvaro Obregón and the Mexican Revolution, Chichester, West Sussex, Reino Unido, Malden, Massachusetts, Wiley-Blackwell, 2011.

CABrera, Luis, La reconstitución de los ejidos de los pueblos como medio de suprimir la esclavitud del jornalero mexicano; Discurso pronunciado en la Cámara de Diputados el 3 de diciembre de 1912, México, Tip. de Fidencio S. Soria, 1913, en Silva Herzog, 1961, t. II, pp. 277-310.

CÁrdenas, Lázaro, Palabras y documentos públicos de Lázaro Cárdenas 19281970, México, Siglo Veintiuno Editores, 1978, tomo I.

Cárdenas, Lázaro, Seis años de gobierno al servicio de México, 1934-1940, México, Departamento de Plan Sexenal, Secretaría de Gobernación, 1940.

Ceballos Garibay, Héctor, Francisco J. Múgica. Crónica política de un rebelde, México, Ediciones Coyoacán, 2004.

Compendio estadístico 1951, México, Secretaría de Economía, Dirección General de Estadística, 1952. 
Congreso de la Unión XXVII, Cámara de Diputados, Síntesis de su labor (abril a diciembre de 1917), México, Imprenta de la Cámara de Diputados, 1918.

Córdova, Arnaldo, La ideología de la Revolución Mexicana: la formación del nuevo régimen, México, Era, 1985.

Cosío Villegas, Daniel (coord.), Historia general de México, México, El Colegio de México, 1988, tomo 2.

Craig, Ann L., The First Agraristas. An Oral History of a Mexican Agrarian Reform Movement, Berkeley, University of California Press, 1983.

Cumberland, Charles, Mexico: The Struggle for Modernity, Londres, Oxford y Nueva York, Oxford University Press, 1968.

Domínguez Rascón, Alonso, La política de la reforma agraria en Chibuabua, 1920-1924: sus efectos hasta 1940, México, Instituto Nacional de Antropología e Historia, 2003.

Dulles, John W. F., Ayer en México. Una crónica de la revolución, 1919-1936, traducción de Julio Zapata, México, Fondo de Cultura Económica, 1977.

Eckstein, Salomón, El ejido colectivo en México, México, Fondo de Cultura Económica, 1978.

Elizondo, Carlos, The Concept of Property of the 1917 Mexican Constitution, México, Centro de Investigación y Docencia Económicas, 1993.

Escobar Ohmstede, Antonio y Matthew Butler (eds.), Mexico in Transition: New Perspectives on Mexican Agrarian History, Nineteenth and Twentieth Centuries, Mexico, Centro de Investigaciones y Estudios Superiores en Antropología Social; Austin, Texas, LLILAs, 2013.

Fabila, Gilberto y Francisco A. URsÚA, Fraccionamiento de latifundios: bases para la ley federal sobre esta materia, reglamento del artículo 27 constitucional, México, Imprenta de la Cámara de Diputados, 1925.

Fabila, Manuel, Cinco siglos de legislación agraria (1493-1940), México, Secretaría de la Reforma Agraria, Centro de Estudios Históricos del Agrarismo en México, 1981. 
Falcón, Romana, Revolución y caciquismo: San Luis Potosí, 1910-1938, México, El Colegio de México, 1984.

Foster, George M., Empire's Children. The People of Tzintzuntzan, Smithsonian Institution Publication núm. 6, México, Imprenta Nuevo Mundo, 1948.

Fuentes, Carlos, La muerte de Artemio Cruz, Santiago de Chile, Editorial Andrés Bello, 1993.

Ginzberg, Eitan, "State Agrarianism versus Democratic Agrarianism: Adalberto Tejeda's Experiment in Veracruz, 1928-32", en Journal of Latin American Studies, 30: 2 (mayo 1998), pp. 341-372.

GinzBerg, Eitan, "El retorno de la ideología: la presidencia de Lázaro Cárdenas, 1934-1940”, en Benítez Salazar, 2009, pp. 269-320.

Ginzberg, Eitan, Lázaro Cárdenas gobernador de Michoacán, 1928-1932, Zamora y Morelia, El Colegio de Michoacán, Universidad Michoacana de San Nicolás de Hidalgo, 1999.

González Casanova, Pablo, La democracia en México, México, Era, 1991.

Guerra Manzo, Enrique, "Los intermediarios políticos y la reconstrucción del poder local en Michoacán (1920-1940)", tesis de doctorado en historia, México, El Colegio de México, 1998.

Gutelman, Michel, Capitalismo y reforma agraria en México, traducción de Félix Blanco, México, Era, 1978.

Hall, Linda B., "Álvaro Obregón and the Politics of Mexican Land Reform, 1920-1924”, en The Hispanic American Historical Review, 60: 2 (mayo 1980), pp. 213-238.

Hansis, Randal George, "Álvaro Obregón, the Mexican Revolution and the Politics of Consolidation”, tesis de doctorado, Nuevo México, University of New Mexico, 1971.

Hewitt de Alcántara, Cynthia, La modernización de la agricultura mexicana, traducido por Félix Blanco, México, Siglo Veintiuno Editores, 1978.

Ibarra Mendibil, Jorge Luis, Ejido y control estatal, México, Universidad Autónoma Metropolitana-Azcapotzalco, 1981. 
Infield, Henrik F. y Koka FreIER, People in Ejidos: A Visit to the Cooperative Farms of Mexico, Nueva York, Frederick A. Praeger, 1954.

Janvry, Alain de et al., "Ejido Sector Reforms: From Land Reform to Rural Development”, en Randall, 1996, pp. 71-106.

Katz, Friedrich, The Life and Times of Pancho Villa, Stanford, California, Stanford University Press, 1998.

KNight, Alan, "Land and Society in Revolutionary Mexico: The Destruction of the Great Haciendas”, en Mexican Studies/Estudios Mexicanos, 7: 1 (invierno 1991), pp. 73-104.

Knight, Alan, "Popular Culture and the Revolutionary State in Mexico, 1910-1940", en The Hispanic American Historical Review, 74: 3 (ago. 1994), pp. 393-444.

Knight, Alan, “The Ideology of the Mexican Revolution, 1910-1940”, en Estudios Interdisciplinarios de América Latina y el Caribe, 8: 1 (ene.-jun. 1997), pp. 77-109.

LEÓN, Bernardo M. de, "La lucha por el exterminio del latifundio en Nayarit, del General Martín Espinoza al gobernador Francisco Parra, 1910-1940”, en Moreno García (coord.), 1982, pp. 167-182.

Ley de 19 de diciembre de 1925 sobre repartición de tierras y constitución de patrimonio ejidal y su reglamento de 4 de marzo de 1926, México, Comisión Nacional Agraria, 1926.

Ley de tierra libre para los mexicanos en México (1923), México, Secretaría de Agricultura y Fomento, Talleres Gráficos de la Nación, 1926.

Los presidentes de México ante la nación, México, Imprenta de la Cámara de Diputados, 1966, t. III (1912-1934).

Luna Arroyo, Antonio y Luis G. Alcerreca (eds.), Diccionario de derecho agrario, México, Porrúa, 1982.

Martínez Assad, Carlos, Breve historia de Tabasco, México, El Colegio de México, Fideicomiso Historia de las Américas, Fondo de Cultura Económica, 1996. 
McCutchen McBride, George, The Land Systems of Mexico, Nueva York, Octagon Books, 1971.

Medin, Tzvi, El minimato presidencial: historia politica del maximato, 19281935, México, Era, 1983.

Medin, Tzvi, El sexenio alemanista: ideología y praxis política de Miguel Alemán, México, Era, 1990.

Medin, Tzvi, Ideología y praxis política de Lázaro Cárdenas, México, Siglo Veintiuno Editores, 1987.

Memoria del Senado de la República. 1958-1964. Labores legislativas, políticas y sociales, desarrolladas durante el ejercicio de las XLIV y XLV legislaturas federales, México, Talleres de Imprenta y Offset “Policromía”, 1964.

Meyer, Lorenzo, “El primer tramo del camino”, en Cosío Villegas, 1988, pp. $1375-1548$.

Meyer, Lorenzo, "Historical Roots of the Authoritarian State in Mexico", en Reyna y Weinert, 1977, pp. 3-22.

Meyer, Lorenzo, "Los límites de la política cardenista: la presión externa”, en Revista de la Universidad de México, xxv: 5 (mayo 1971), pp. 1-8.

Monroy Durán, Luis, El último candillo. Apuntes para la historia de México acerca del movimiento armado de 1923 en contra del gobierno constituido, México, J. S. Rodríguez, 1924.

Moreno García, Heriberto (coord.), Después de los latifundios: la desintegración de la gran propiedad agraria en México, III Coloquio de Antropología e Historia Regionales, agosto de 1981, México, El Colegio de Michoacán y FONAPAS Michoacán, 1982.

Obregón, Álvaro, "Carta al Licenciado Roque Estrada (19 de diciembre de 1919)”, en Bassols, 1976, pp. 137-138.

Oikión Solano, Verónica, Los hombres del poder en Michoacán, 1924-1962, Zamora, Mich., El Colegio de Michoacán, 2004.

Orozco, Wistano Luis, Los ejidos de los pueblos, México, Ediciones El Caballito, 1975. 
Padilla Calderón, Esther, Agua, poder y escasez: la construcción social de un territorio en un ejido sonorense, 1938-1955, México, El Colegio de Sonora, 2012.

Palomares Peña, Noé G., Propietarios norteamericanos y reforma agraria en Chibuabua, 1917-1942, México, Universidad Autónoma de Ciudad Juárez, 1991.

PEÑA, Moisés T. de la, El pueblo y su tierra: mito y realidad de la reforma agraria en México, México, Cuadernos Americanos, 1964.

Portes Gil, Emilio, Autobiografía de la revolución mexicana. Un tratado de interpretación histórica, México, Instituto Mexicano de Cultura, 1964.

Purnell, Jennie, Popular Movements and State Formation in Revolutionary Mexico: The 'Agraristas' and 'Cristeros' of Michoacán, Durham, Carolina del Norte, Duke University Press, 1999.

Quinto censo de población (1930). Resumen general, México, Secretaría de la Economía Nacional, Dirección General de Estadística, 1934.

Randall, Laura (ed.), Reforming Mexico's Agrarian Reform, Armonk, Nueva York, M. E. Sharpe, 1996.

Recopilación de leyes de los reynos de las Indias, mandadas imprimir y publicar por la magestad católica del rey Don Carlos II, nuestro señor, Madrid, Julián de Paredes, 1681, Libro VI, Título III, Ley VIII.

"Reglamento de la expedición y amortización de los bonos de la deuda pública agraria”, en Luna Arroyo y Alcerreca, 1982, pp. 232-237.

Resultados del IX Censo Ejidal 2007, México, Instituto Nacional de Estadística y Geografía (INEGI), 2007.

Reyes Osorio, Sergio et al., Estructura agraria y desarrollo agrícola en México: estudio sobre las relaciones entre la tenencia y uso de la tierra y el desarrollo agrícola de México, México, Fondo de Cultura Económica, 1974.

Reyna, José Luis y Richard S. Weinert (eds.), Authoritarianism in Mexico, Philadelphia, Pennsylvania, Institute for the Study of Human Issues, 1977. 
Salas Landa, Mónica M., "Enacting Agrarian Law: The Effects of Legal Failure in Post-Revolutionary Mexico", en Journal of Latin American Studies, 47: 4 (nov. 2015), pp. 700-714.

Salazar Adame, Florencio, La cuestión agraria en la transición, México, Secretaría de la Reforma Agraria, 2004.

Sánchez DíAz, Gerardo (coord.), La Revolución en Michoacán, 1900-1926, Morelia, Michoacán, Coordinación de la Investigación Científica, Departamento de Historia, 1987.

SÁnchez GonzÁlez, José, "El marco jurídico de la Reforma Agraria en el periodo de 1940 a 1981”, en Moreno García, 1982, pp. 233-258.

SÁNCHez Rodríguez, Martín, Grupos de poder y centralización política en México. El caso Michoacán 1920-1924, México, Instituto Nacional de Estudios Históricos de la Revolución Mexicana, 1994.

Silva Herzog, Jesús, El agrarismo mexicano y la reforma agraria. Exposición y crítica, México, Fondo de Cultura Económica, 1985.

Silva Herzog, Jesús (ed.), La cuestión de la tierra, México, Instituto Mexicano de Investigaciones Económicas, 1961, tomos I-IV.

Simpson, Eyler N., The Ejido: Mexico's Way Out, Chapel Hill, Carolina del Norte, The University of North Carolina Press, 1937.

Skerritt Gardner, David, “Qué es la Mano Negra”, en Anuario III, Jalapa, Universidad Veracruzana, Centro de Estudios Históricos, Instituto de Investigaciones Humanísticas, 1981, pp. 129-138.

Tannenbaum, Frank, The Mexican Agrarian Revolution, Hamden, Connecticut, Archon Books, 1968.

Tello, Carlos, La tenencia de la tierra en México, México, Universidad Nacional Autónoma de México, 1968.

The Mexican Constitution of 1917 compared with the Constitution of 1857, traducción y coedición de H. N. Branch y L. S. Rowe, Philadelphia, The American Academy of Political and Social Science, 1917, pp. 15-25. 
UlloA, Berta, "La constitución de 1917”, en Luis GonZÁlez y GonZÁlez (coord), Historia de la revolución mexicana, periodo 1914-1917: la encrucijada de 1915, México, El Colegio de México, 1983, vol. 6.

UrReA, Blas (Luis Cabrera), Veinte años después: el balance de la revolución, la campaña presidencial de 1934, las dos revoluciones, México, Ediciones Botas, 1938.

Warman, Arturo et al. (dirs.), La transformación agraria. Origen, evolución, retos, testimonios, México, Secretaría de la Reforma Agraria, 1998.

West, Robert, Cultural Geography of the Modern Tarascan Area, Smithsonian Institution Publication núm. 7, Washington, United States Government Printing Office, 1948.

WILKIE, James W., La revolución mexicana (1910-1976): gasto federal y cambio social, México, Fondo de Cultura Económica, 1978.

Wolfe, Mikael, “The Sociolegal Redesignation of Ejido Land Use, 18561912”, en Escobar Ohmstede y Butler, 2013, pp. 291-318.

Womack JR., John, Zapata and the Mexican Revolution, Harmondsworth, Middlesex, Penguin Books, 1972. 
